\title{
Dynamic characterization of progressively damaged segmental masonry arches with one settled support: experimental and numerical analyses
}

\author{
Maria-Giovanna Masciotta \\ Department of Engineering and Geology, University G. d'Annunzio of Chieti-Pescara, Italy \\ Institute of Information Science and Technologies "A. Faedo", ISTI-CNR, Pisa, Italy \\ g.masciotta@unich.it, https://orcid.org/0000-0003-2364-3490
}

Daniele Pellegrini, Maria Girardi, Cristina Padovani Institute of Information Science and Tecbnologies "A. Faedo", ISTI-CNR, Pisa, Italy daniele.pellegrini@isti.cnr.it, bttps://orcid.org/0000-0002-3416-771X maria.girardi@isti.cnr.it, bttps:/ /orcid.org/0000-0002-7358-5607 cristina.padovani@isti.cnr.it, bttps:/ orcid.org/0000-0002-2467-569X

Alberto Barontini, Paulo B. Lourenço ISISE, Department of Civil Engineering, University of Minbo, Guimarães, Portugal albe.barontini@gmail.com, https:/ /orcid.org/0000-0001-8377-8149

pbl@civil.uminbo.pt, bttp:// orcid.org/0000-0001-8459-0199

Daniele Brigante, Giovanni Fabbrocino Structural and Geotechnical Dynamics Laboratory, University of Molise, Campobasso, Italy daniele.brigante@unimol.it, bttps:/ /orid.org/0000-0001-5538-2024 giovanni.fabbrocino@unimol.it, https:/ /orcid.org/0000-0002-4918-5398

ABSTRACT. This paper aims to explore the dynamic behavior of a segmental masonry arch subjected to increasing horizontal displacements of one support. To this end, output-only dynamic identification techniques are first used to track the evolution of the dynamic features of the system under progressive damage scenarios and evaluate their sensitivity to settlementinduced cracks. Considerations on the structural response of the segmental arch up to failure are also included. Then, a numerical procedure coupling linear perturbation and modal analysis is applied to simulate the dynamic behavior of the arch over consecutive scenarios, taking into account the influence of the damage on the structure's dynamic properties in an automatic way. The combination of experimental and numerical analyses allows to fully investigate the dynamics of the cracked masonry arch and to shed light on

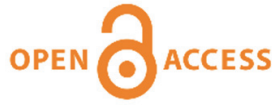

Citation: Masciotta, M.G., Pellegrini, D., Brigante, D., Barontini, A., Lourenço, P.B., Girardi, M., Padovani, C., Fabbrocino, G. Dynamic characterization of progressively damaged segmental masonry arches with one settled support: experimental and numerical analyses, Frattura ed Integrità Strutturale, 51 (2020) 423-441.

Received: 13.06.2019

Accepted: 06.11.2019

Published: 01.01.2020

Copyright: (C) 2020 This is an open access article under the terms of the CC-BY 4.0, which permits unrestricted use, distribution, 
relevant aspects about the effects of settlement-induced cracks on the modal blueprints of masonry arches.

KEYWORDS. Masonry arch settlements; Dynamic behavior; Modal analysis; Linear perturbation; Model updating; Nonlinear elasticity. and reproduction in any medium, provided the original author and source are credited.

\section{INTRODUCTION}

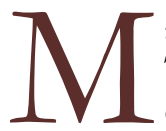

asonry arches are among the most used structural systems in many worldwide historical buildings and bridges. The first arches appeared as early as the second millennium B.C. in Mesopotamian architecture. The great ancient civilizations, like the Egyptians, the Babylonians and the Assyrians, knew about the arch and began to exploit it as a basic structural system to span large areas and enclose spaces. However, the systematic use of masonry arches only started with the ancient Romans, who learned the arch from the Etruscans, refined it and tapped its full potential for above ground buildings and bridges, erecting arch structures throughout the empire [1]. Many of those structures have survived almost unimpaired for centuries and are still in use today. Indeed, the nature of the masonry material combined with the resistant virtues of the arch form makes these structural systems durable and surprisingly resistant to high compression loads. Yet, during their lifespan, masonry arches are exposed to several threats that can adversely affect their bearing capacity and stability, such as structural damages due to horizontal actions or excessive vertical loads originated by the increased traffic demand, materials degradation and springing settlements. In this regard, many research works have been devoted in the last years to investigating the mechanics of masonry arches up to failure for different loading conditions [2-7] and arch shapes [8] as well as considering the influence of geometrical irregularities [9, 10], materials nonlinearity [11], arch-fill interaction $[11,12]$ and localized damages $[13,14]$. Apart from a few exceptions, a large amount of this literature focused on simplified uni- or bi-dimensional problems with the aim of shedding light on the collapse mechanisms of masonry arches to evaluate the minimum load multipliers and ultimate load carrying capacity. To this end, the most common approaches used by the international community working on these topics are the limit analysis and the finite element method, or a combination of both [15].

However, despite the great quantity of research devoted to the static and dynamic analysis of masonry arches, not all the aspects related to its structural behavior have been completely explored. For instance, studies on the actual response of arched structures subjected to springing settlements are still limited and mainly focused on the evaluation/prediction of the most probable failure modes for a variety of different semicircular or pointed arch geometries and settlement mechanisms [16-20], through analytical and/or advanced numerical procedures. Much less attention is paid to segmental masonry arches, which are indeed more prone to lateral movements of the abutments because of the higher horizontal thrust deriving from their shape (the flatter the arch, the greater the thrust). Furthermore, to the authors' knowledge, no study on the effects of settlement-induced cracks on the dynamic blueprints of masonry arches has been ever addressed. As settlements represent one of the main causes of collapse in arched structures, the correct dynamic characterization of the nonlinear behavior of masonry arches undergoing this type of phenomena is fundamental to timely detect the stiffness degradation and consequent strength reduction resulting from the gradual progression of support displacements, thereby preventing local damages and unexpected failures. Indeed, the sensitivity of dynamic properties to structural damage is widely recognized within the scientific community and many works have demonstrated the importance of tracking such features to monitor the structural health and identify the onset of damage at the earliest possible stage, even when not yet detectable by visual inspections [2124].

In light of the above considerations, the present contribution aims at thoroughly investigating the three-dimensional dynamic behavior of a segmental masonry arch under increasing horizontal settlements of one support. To rigorously address this problem, the adopted strategy combines both experimental and numerical methods: the former for the realtime simulation of the studied phenomenon and the direct estimation of damage-sensitive dynamic features for the calibration of the subsequent numerical model; the latter for the correct reproduction of the actual dynamic behavior of the masonry arch taking into account the non-linear behavior of the materials and the effects that settlement-induced cracks have on the dynamic properties of masonry structures. Accordingly, the article is organized in two main parts: the first one is dedicated to the experimental analysis of the masonry arch and the second one focuses on the numerical simulations. The experimental investigations have been carried out in the Structural Laboratory of the University of Minho in Guimarães (Portugal) and the results obtained from the tests have been exploited as reference information for the subsequent modal analyses performed in the context of nonlinear elasticity through a non-commercial software developed by the Mechanics of Materials and Structures Laboratory of ISTI-CNR (Italy), namely the NOSA-ITACA code. The cross-validation with the 
experimental counterpart allows to verify the reliability of the non-standard numerical procedure adopted to simulate the evolution of the dynamic behavior of settled masonry arches with reasonable accuracy.

\section{EXPERIMENTAL TESTING}

he segmental masonry arch investigated in this work was built and tested in the structural laboratory of the Institute of Bio-Sustainability of the University of Minho (Guimarães, Portugal). The small-scale arch was progressively damaged by applying uniform increasing displacements at one support and, after each displacement stage, dynamic tests were performed to measure the dynamic response of the system and follow its stiffness degradation due to the occurrence of structural damage. Finally, in order to gain a better insight into the failure mechanisms of masonry arches on spreading support, displacements were increased up to collapse, allowing to analyze the hinge position throughout the development of the mechanism as well as to estimate the ultimate displacement of the arch.

\section{Description of the arch and static damage tests}

The arch specimen consists of four rows of 39 brick units $\left(100 \times 75 \times 50 \mathrm{~mm}^{3}\right)$ assembled with staggered lime mortar joints and it is characterized by a nominal span of $1900 \mathrm{~mm}$, a springing angle of $40^{\circ}$, a nominal net rise of $430 \mathrm{~mm}$ and a $75 \mathrm{~mm}$ radial thickness (Fig.1). The structure is symmetrically loaded with two lime bags of $25 \mathrm{~kg}$ each (corresponding to about $50 \%$ of the arch weight), aiming at reproducing the weight of backfill material typical of masonry arch bridges, and is supported by two concrete abutments, one fixed to the floor by bolts (left support) and the other set on a simple system with lateral roulette wheels (right support) featuring a movable springing along the horizontal direction.

With the aim of investigating the support settlements effects on the dynamic behavior of the segmental arch, a displacementcontrolled test is carried out to induce five unrecoverable Damage Scenarios (DSs). Outward movements in horizontal direction are imposed to the right support with a hydraulic jack, whose displacement is simultaneously measured by a Linear Variable Displacement Transducer (LVDT). Additionally, two LVDTs are used to control the uniform sliding of the movable support and two LVDTs are employed to measure the arch displacements at the keystone and left springer, respectively (Fig.1a).
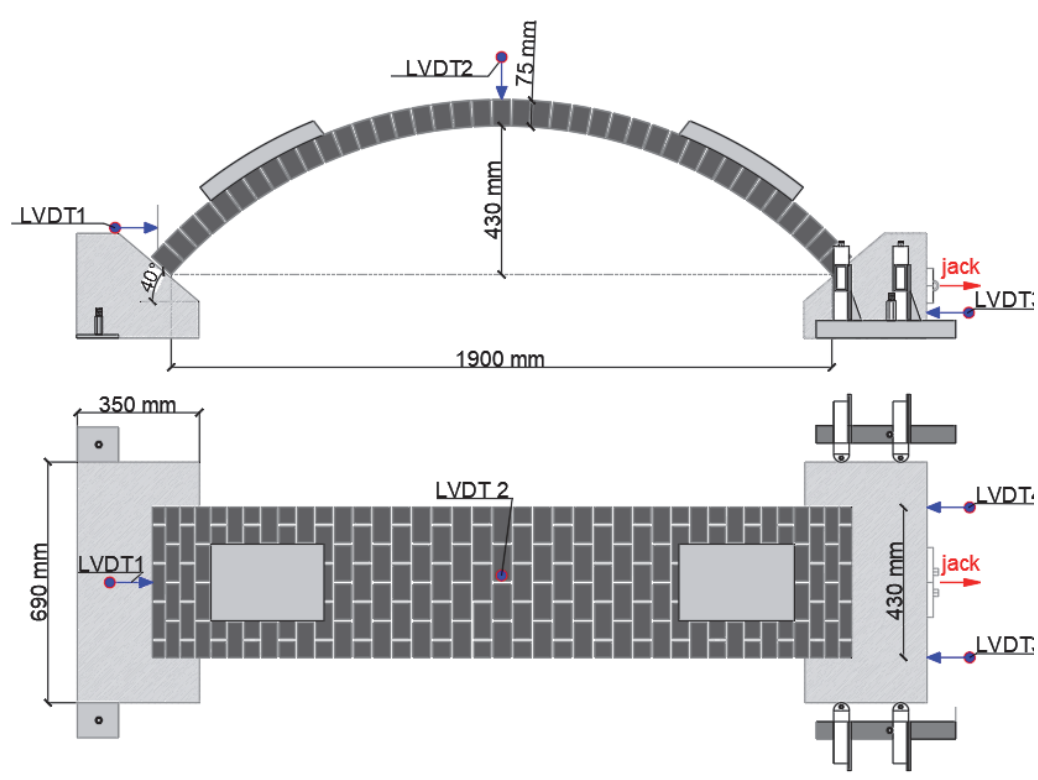

(a)

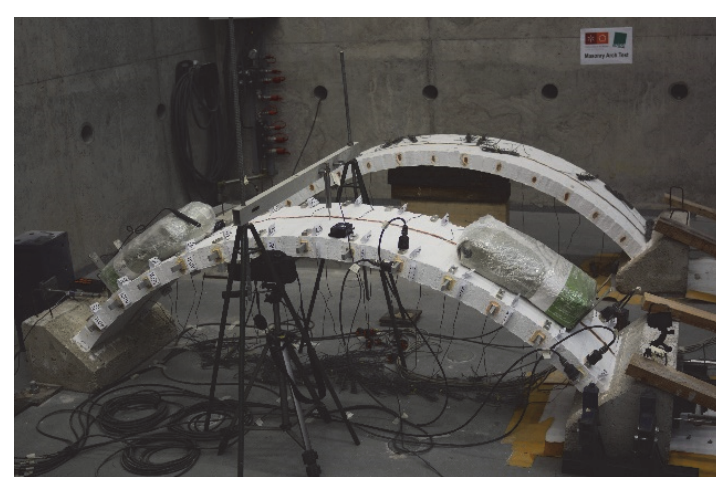

(b)

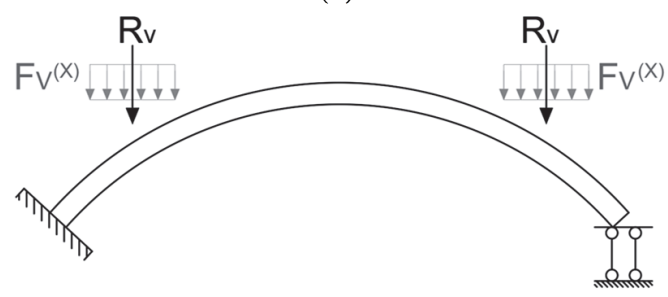

(c)

Figure 1: Arch specimen: (a) geometry with test layout; (b) view of the test apparatus; (c) static scheme.

Increasing displacement rates are applied in five stages up to reaching a final value of $3 \mathrm{~mm}$ (Tab.1). the scope of the experimental test in this first phase is to cause very little visual damage to the arch so as to quantitatively assess the effects that incipient settlement-induced cracks can have on its global dynamic behavior. It is noted that the typical experimental 
scheme used in literature for masonry arches consists in performing force-controlled static tests with increasing loads applied at a quarter of the span. In spite of being a well-established procedure, this testing scheme does present clear disadvantages when dealing with damage identification problems as it results in recoverable damage scenarios because of the closure of cracks during the unloading phases, which is indeed overcome with the adopted experimental scheme. On the other hand, the placement of lime bags on the arch backs allows to evaluate the possible influence of backfill material on the global modal parameters of the arched structure.

As the support settles, three passing cracks progressively appear at the mortar-brick interfaces: the first crack $c_{1}$ is located at the intrados, in the left region of the keystone; the second and the third cracks, denoted by $c_{2}$ and $c_{3}$, appear at the extrados of the left (fixed support) and right (moving support) skewbacks, respectively. The crack pattern observed at the end of the five stages is presented in Fig. 2.

\begin{tabular}{cccc}
\hline Stage & Name & Acronym & Settlement $[\mathrm{mm}]$ \\
0 & Reference Scenario (with Weight) & RSW & - \\
1 & Damage Scenario 1 & DS1 & 0.4 \\
2 & Damage Scenario 2 & DS2 & 0.5 \\
3 & Damage Scenario 3 & DS3 & 0.6 \\
4 & Damage Scenario 4 & DS4 & 0.7 \\
5 & Damage Scenario 5 & DS5 & 0.8 \\
Tot. & - & - & 3.0 \\
\hline
\end{tabular}

Table 1: Support settlements applied over different damage scenarios.
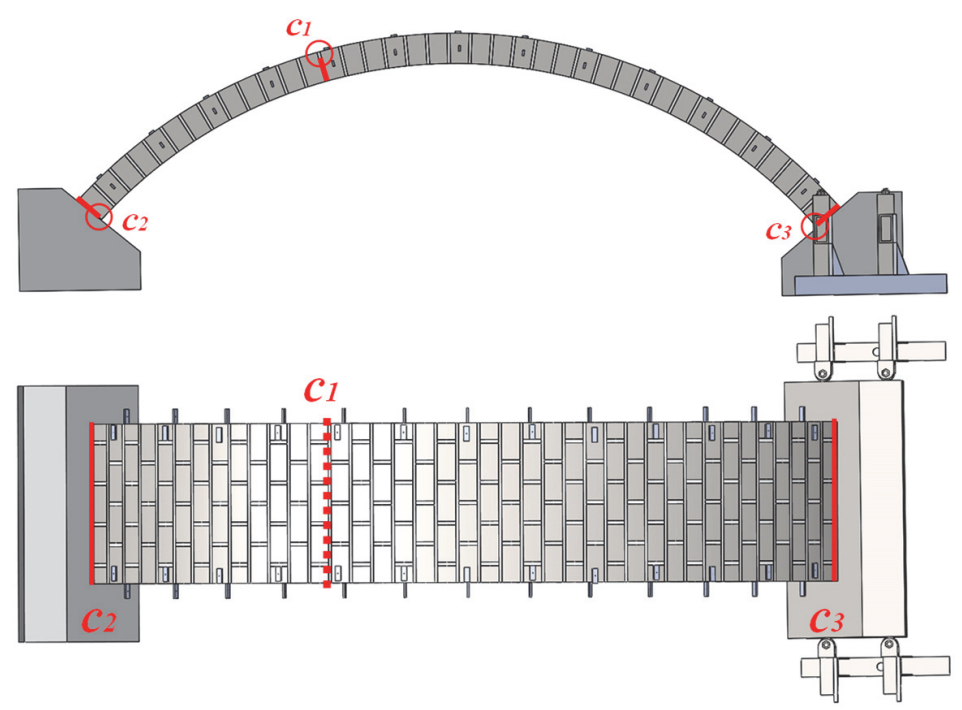

(a)

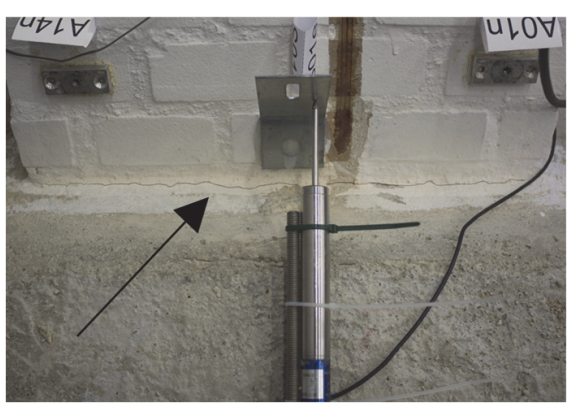

(b)

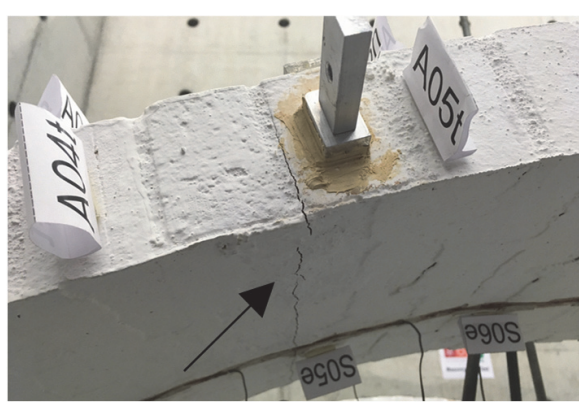

(c)

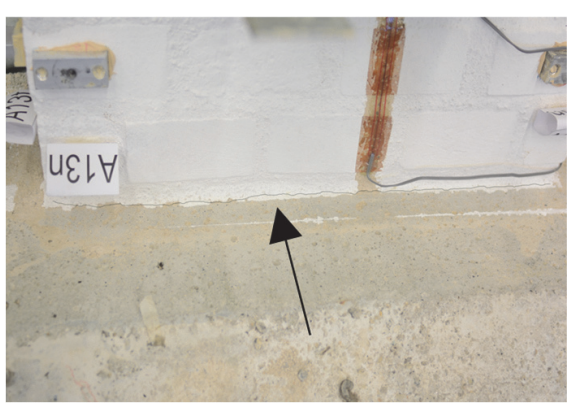

(d)

Figure 2: Crack pattern after $3 \mathrm{~mm}$ horizontal settlement of the right support: (a) crack location; (b) crack $c_{2}$; (c) crack $c_{1}$; (d) crack $c_{3}$. 
Horizontal, vertical and inclined settlements at the support of an arch are responsible for the formation of three crack hinges, which can transform the structure into a mechanism if the thrust line becomes tangent at the arch boundary in enough points [16, 27]. Considering segmental arches subjected to horizontal settlements of one support, the typical mechanism consists of symmetric crack hinges that open alternatively at the intrados and extrados of the arch depending on the inwards or outwards direction of the settlement. However, literature studies highlighted that the position of internal hinges can vary with the arch geometry [16] as well as with the increase of the horizontal displacement at the support [20]. A more extensive discussion on the hinge position and collapse mechanism regarding the arch object of analysis is provided hereinafter.

\section{Modal testing and evolution of dynamic features with progressive settlements}

It is well-known that modal parameters are related to the physical and mechanical properties of a structure, like mass, stiffness, and energy dissipation. Such a relationship implies that any structural change a system may undergo over time will be reflected by changes in its modal properties. Thus, to analyze the evolution of the modal features of the arch with spreading support and to track its stiffness degradation with progressive damage, dynamic identification tests are performed in the damage scenario (DS) reached after each displacement stage.

Given the non-negligible background noise of the laboratory environment, the vibration response of the structure is measured using both ambient excitations and random finger tapping so as to ensure a fairly high signal-to-noise ratio, without violating the assumption of stationary Gaussian white noise input on which operational modal analysis relies. Eight high-sensitivity accelerometers (model PCB 393B12, 0.15 to $1000 \mathrm{~Hz}$ frequency range, $10000 \mathrm{mV} / \mathrm{g}$ sensitivity, $8 \mu \mathrm{g}$ resolution) and twelve setups - each one consisting of four fixed reference sensors and four moving sensors - are employed to acquire the response processes of 26 points evenly spaced along the front and back edges of the arch, for a total number of 52 acceleration responses, 26 in normal direction and 26 in tangential direction (Fig. 3).

Aiming at the direct estimation of modal curvatures, which are notably more sensitive to structural damage as compared to other modal parameters [23, 24], twenty-six linear strain gauges (series PL-120-11-5L) are also used to measure the strains both at the intrados and extrados of the arch middle line (Fig. 3). The choice of such a dense sensor distribution including accelerometers and strain gauges is driven by the necessity to obtain a very good resolution in terms of modal estimates, especially as far the mode shapes are concerned. To ensure an acquisition window of at least 2000 times the fundamental period of the arch, signals are sampled at $400 \mathrm{~Hz}$ for a minimum duration of $180 \mathrm{~s}$ ( $60 \mathrm{~s}$ in the case of random fingertips), resulting in $72.000(24.000)$ data points per channel.
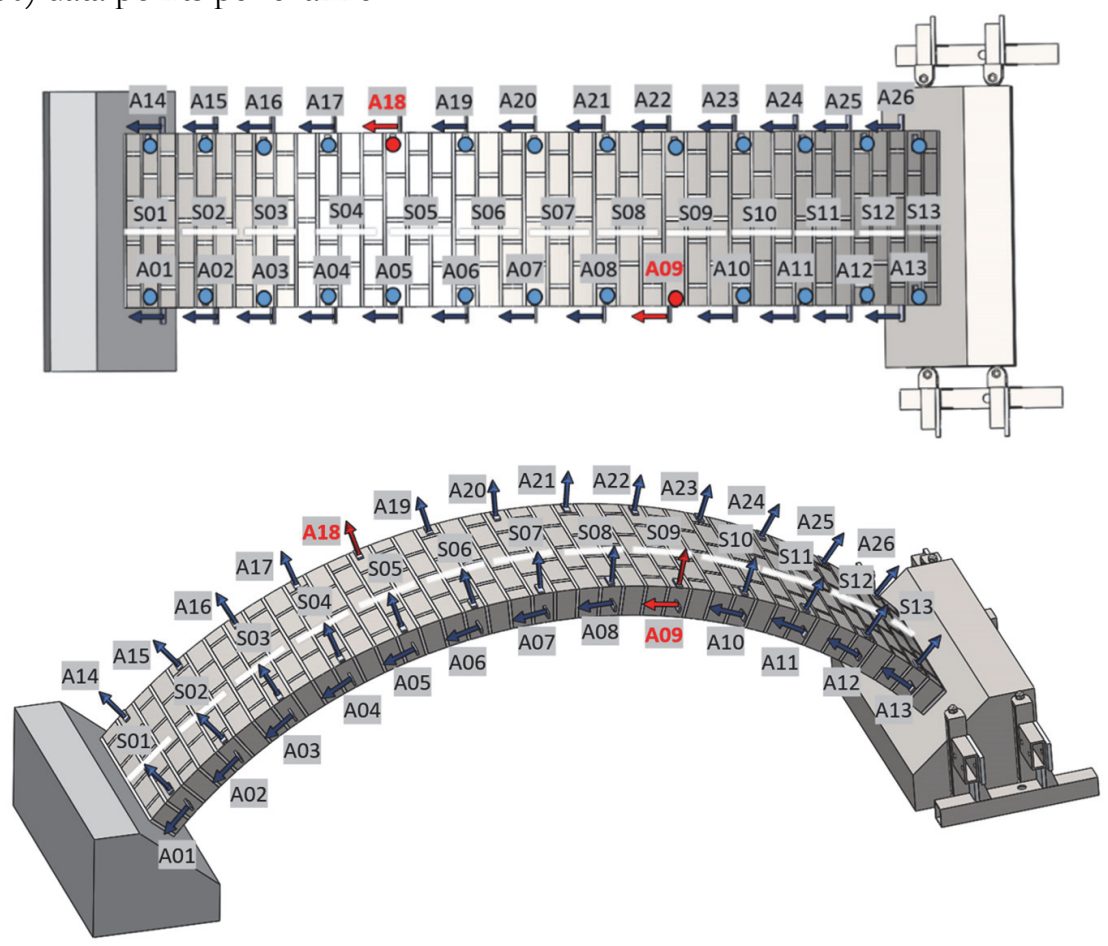

Figure 3: Sensor layout for the dynamic identification tests. Accelerometers and strain gauges are denoted by Ai and Si, respectively; reference sensors are indicated in red. 
In order to identify the dynamic properties of the structure over the different DSs, the time-dependent nodal response processes recorded before applying any support displacement (undamaged configuration) are processed and analyzed first. Two well-known and complementary modal estimators implemented in the software ARTeMIS Modal [28] are employed for the feature extraction: the Enhanced Frequency Domain Decomposition (EFDD) and the Stochastic Subspace Identification with Extended Unweighted Principal Component (SSI-UPCX). The results in frequencies, damping ratios and MAC coefficients for the undamaged scenarios, either with (RSW) or without (RS) additional weight, are summarized in Tab. 2, whereas the corresponding mode shapes are displayed in Fig. 4.

\begin{tabular}{cccccccc}
\hline Mode & $f_{\mathrm{RS}}[\mathrm{Hz}]$ & $f_{\mathrm{RSW}}[\mathrm{Hz}]$ & $\Delta f[\%]$ & $\xi_{\mathrm{RS}}[\%]$ & $\zeta_{\mathrm{RSW}}[\%]$ & $\Delta \xi[\%]$ & $\mathrm{MAC}\left(\varphi_{\mathrm{RS}}, \varphi_{\mathrm{RSW}}\right)$ \\
\hline & 37.03 & 30.06 & -23.19 & 0.95 & 1.26 & +24.60 & 1.00 \\
2 & 58.64 & 50.95 & -15.09 & 0.88 & 3.06 & +71.24 & 0.70 \\
3 & 63.56 & 59.44 & -6.93 & 1.02 & 1.22 & +16.39 & 0.93 \\
4 & 100.76 & 95.23 & -5.81 & 0.97 & 2.12 & +54.25 & 0.90 \\
5 & 122.67 & 120.62 & -1.70 & 1.25 & 2.97 & +57.91 & 0.71 \\
6 & 125.06 & - & - & 1.03 & - & - & - \\
7 & 146.21 & 134.02 & -9.10 & 1.46 & 4.19 & +65.16 & 0.67 \\
$\operatorname{Avg}$ & - & - & -10.30 & - & - & +48.26 & - \\
\hline
\end{tabular}

Table 2: Comparison between estimated frequencies $f$ and damping ratios $\xi$ of the arch for RS and RSW scenarios (torsional modes are highlighted in grey).

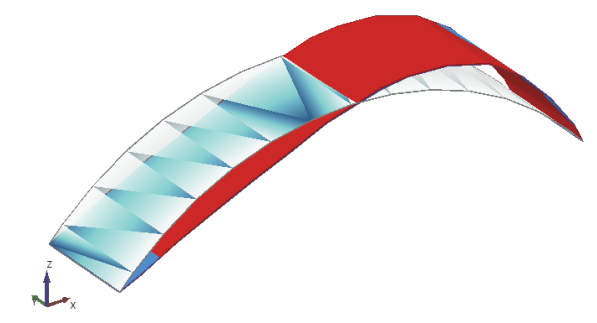

Mode $1(\mathrm{MAC}=1.00)$

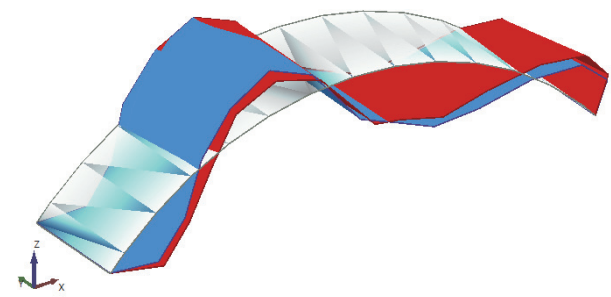

Mode $4(\mathrm{MAC}=0.90)$

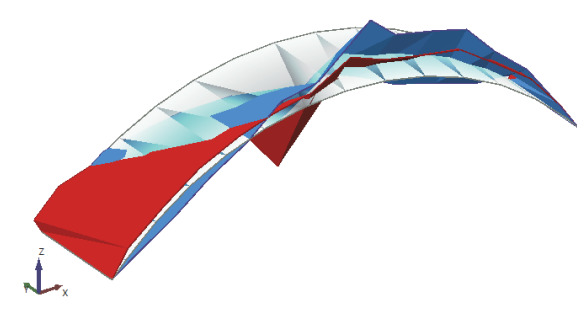

Mode $2(\mathrm{MAC}=0.70)$

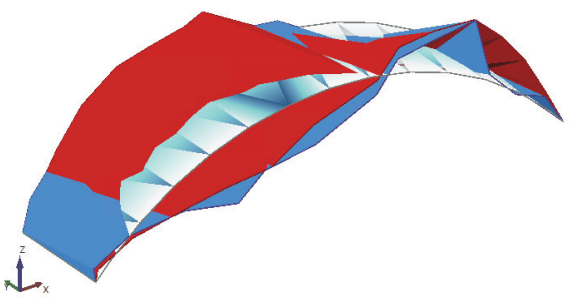

Mode $5(\mathrm{MAC}=0.71)$

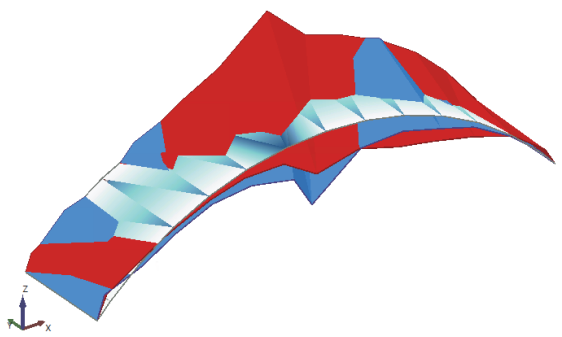

Mode 7 (MAC $=0.67)$

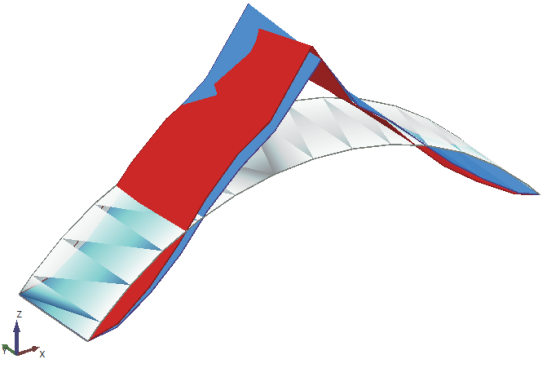

Mode $3(\mathrm{MAC}=0.93)$

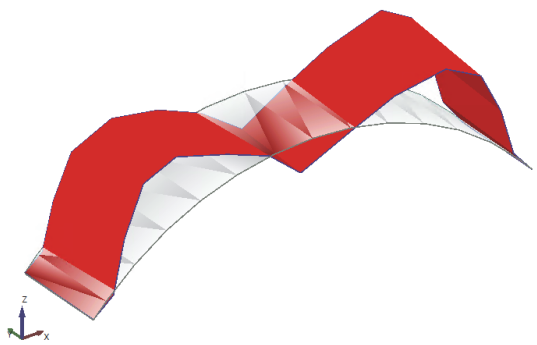

Mode 6

Figure 4: Mode shapes identified in both reference scenarios (undeformed shape in grey, RS in red and RSW in blue). 
Either estimator allows to identify seven vibration modes in the frequency range $37-147 \mathrm{~Hz}$ with damping ratios below $2 \%$ for RS and six vibration modes in the frequency range 30-135 Hz with damping ratios below 5\% for RSW. For the sake of brevity, only the modal features extracted by the SSI-UPCX are presented herein.

A first analysis of the global modal parameters relevant to the two undamaged scenarios shows that, by increasing the overall weight of the arch of about $50 \%$, frequency values decrease of around $10 \%$, while damping values increase of circa $48 \%$. This result is somehow expected assuming a classical Rayleigh damping formulation for the structure [29]. In what concerns the mode shapes, similar configurations are observed for the in-plane vibration response of the arch, with MAC values higher than 0.90 for modes 1, 3 and 4. On the other hand, due to the variation of in-plane and out-of-plane modal components induced by the change in loading conditions, the degree of similarity between corresponding torsional modes decreases, reading MAC values lower than 0.71 for modes 2, 5 and 7, whereas the symmetric mode in Z-direction at 125.06 Hz cannot be identified as a stable mode.

The modal feature extraction process described above is then applied to the output signals collected after each displacement stage. As the support slides, cracks start to propagate, and the arch stiffness degrades with progressive damage. Despite the low displacement rate, this leads to significant changes in the arch eigenfrequencies, recording downshifts of about $36 \%$, $15 \%$ and $22 \%$ for modes 1, 2 and 4, respectively. The frequency results for the six consecutive scenarios (RSW to DS5) are presented in Tab. 3 and Fig. 5. It is worth noting that considerable frequency drops are already observed during DS1, scenario in which the first crack $c_{1}$ appears in the left region of the keystone causing a sudden stiffness reduction in the structure that is reflected by a significant change in the eigenfrequencies of modes 1,4 and 5 . With regard to the modal vectors, the direct comparison between undamaged (RSW) and final damaged (DS5) scenarios reveals remarkable local changes in the high-frequency modes of the arch, but very little changes as far as the main vibration mode is concerned. This is clearly evident by visually inspecting the mode shapes juxtaposed in Fig. 6, whose MAC values are provided below each pair. The larger the differences in modal displacements due to local damage, the higher the MAC sensitivity and the lower its value. Such a result is a direct consequence of the vulnerability that vibration modes featuring a higher number of inflection points exhibit to local structural damage.

\begin{tabular}{cccccccc}
\hline \multirow{2}{*}{ Scenario } & \multicolumn{7}{c}{ Frequencies [Hz] } \\
\cline { 2 - 8 } RSW & Mode 1 & Mode 2 & Mode 3 & Mode 4 & Mode 5 & Mode 6 & Mode 7 \\
DS1 & 30.06 & 50.95 & 59.44 & 95.23 & 120.62 & - & 134.02 \\
DS2 & 26.31 & 50.28 & 59.04 & 80.47 & 113.16 & - & 136.40 \\
DS3 & 23.40 & 48.86 & 58.14 & 75.75 & 111.44 & 121.50 & 130.91 \\
DS4 & 21.44 & 45.14 & 58.27 & 74.97 & 110.60 & 118.71 & 128.84 \\
DS5 & 19.16 & 44.05 & 57.77 & 74.39 & 110.98 & 116.68 & 129.60 \\
$\Delta f[\%]$ & -36.26 & -15.23 & -3.20 & -22.20 & -8.09 & -4.71 & -3.75 \\
\hline
\end{tabular}

Table 3: Eigenfrequencies variation over progressive damage scenarios.

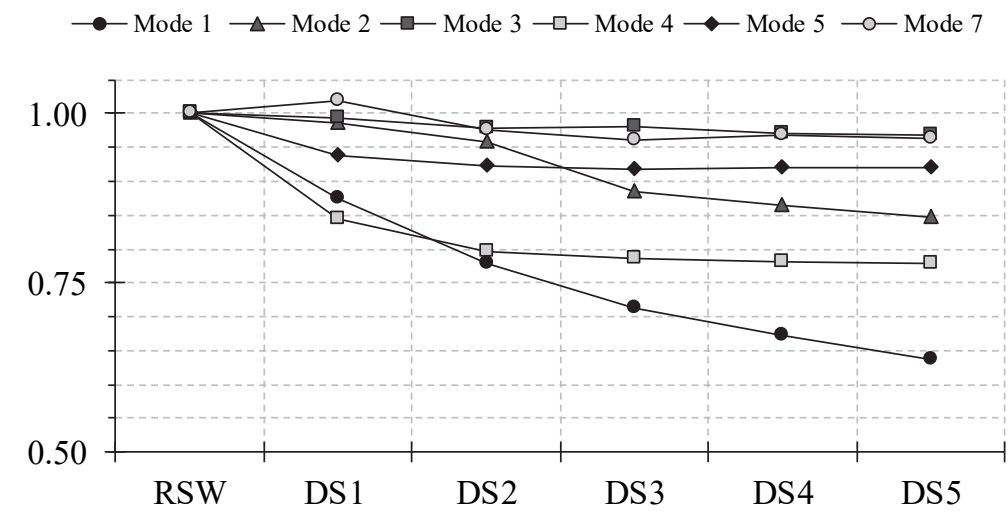

Figure 5: Relative frequency decay with increasing support settlements. 


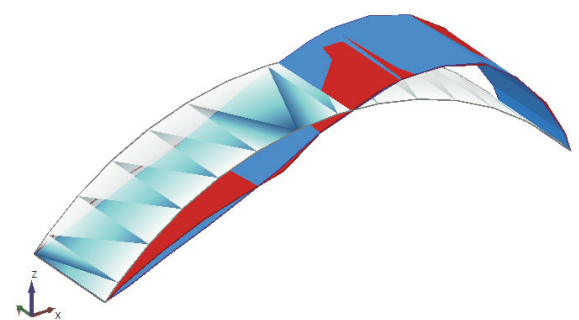

Mode 1 (MAC $=0.98)$

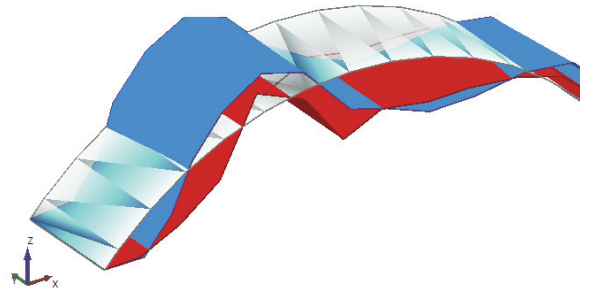

Mode 4 (MAC $=0.60)$

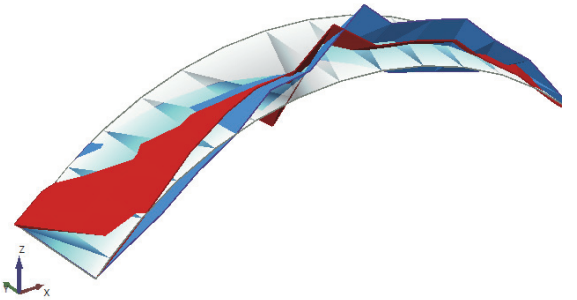

Mode $2($ MAC $=0.72)$

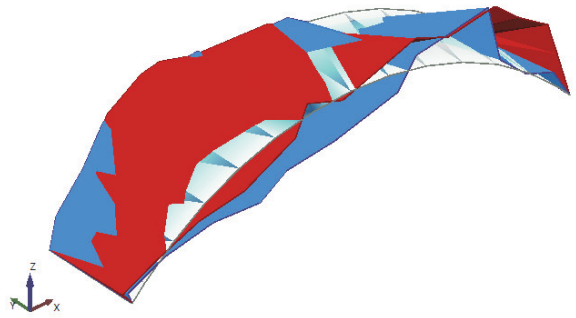

Mode $5(\mathrm{MAC}=0.34)$

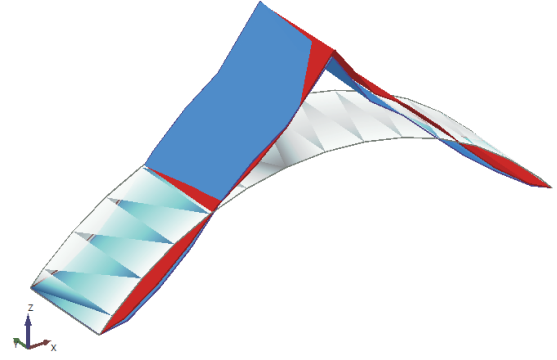

Mode $3(\mathrm{MAC}=0.96)$

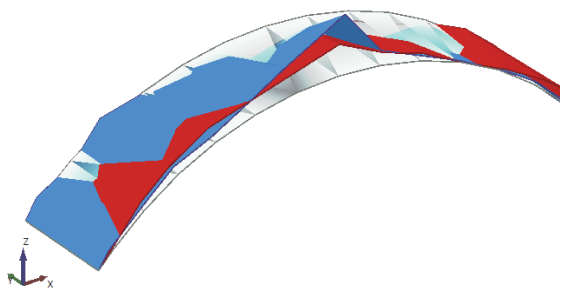

Mode $7(\mathrm{MAC}=0.73)$

Figure 6: Mode shapes comparison between undamaged and last damaged scenarios (undeformed shape in grey, RSW in blue and DS5 in red).

\section{Limit settlement assessment}

The last part of the experimental campaign is devoted to fully explore the response of the settled masonry arch up to failure, also evaluating the limit support displacement and corresponding geometrical configuration. To this end, additional displacement rates are incrementally applied to the movable support in horizontal direction until reaching the final condition. Sufficient releases are required in order to permit a structure to articulate and ultimately collapse. According to the limit analysis, in a skeletal structure a total of $r+1$ releases (e.g. hinges) are required for complete collapse, where $r$ is the degree of redundancy. In a fixed-end semicircular arch $r=3$, so $r+1=4$ hinges form at failure and a three-block mechanism activates; similarly, in a twin span bridge $r+1=7$ hinges are typically observed at failure and a six-block mechanism occurs [30]. Instead, when dealing with settled supports, the degree of redundancy decreases. In particular, if the settled support coincides with one of the hinges, the collapse mechanism coincides with a settled three-hinged arch, i.e. a two-block mechanism that activates at the instant in which the thrust line becomes tangent to the profile of the arch in a further section [19]. With regard to segmental arches on spreading support, the typical failure mechanism usually features three symmetric hinges located alternatively according to the classical configuration intrados-extrados-intrados (Fig. 7). Nevertheless, experimental investigations pointed out that the collapse conditions of masonry arches on spreading support in horizontal direction are dependent on the geometrical parameters of the structure itself, namely curvature radius, thickness and angle of embrace $[16,18]$. The role of uncertainties, particularly those associated with the mechanical parameters of the masonry material, such as the tensile strength of the mortar joints, is also crucial in this regard. Furthermore, hinges may move with the increase of the settlements before reaching the collapse.
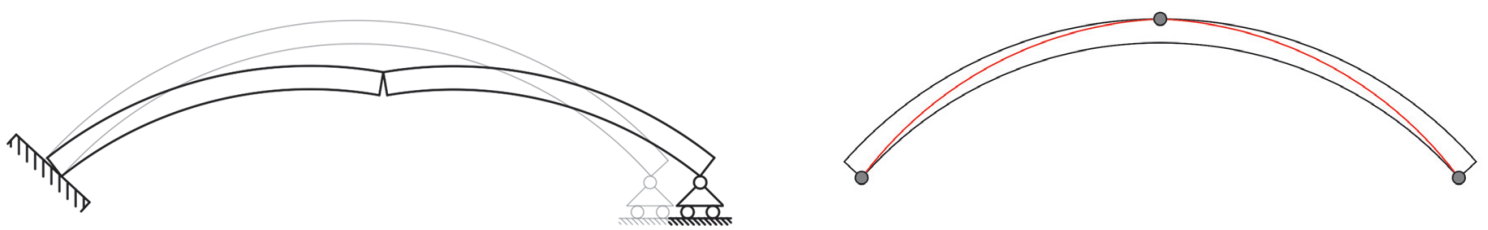

Figure 7: Typical collapse configuration for segmental arches with one settled support in horizontal direction.

For the present case study, the experimental evidence proves that an asymmetric three-hinge configuration occurs, likely imputable to the inhomogeneous distribution of the tensile strength in the mortar joints of the crafted arch; also, the position of the cracks $c_{1}, c_{2}$ and $c_{3}$ characterizing the kinematic collapse does not change from the initial to the final condition. Fig. 8 shows the sequence of kinematic configurations featured by the segmental arch object of analysis, under symmetric loads 
and subjected to horizontal settlements of the right support. Snapshots were taken at the settlement onset (Fig. 8a), in correspondence to a movement of $4.5 \mathrm{~cm}$ (Fig. 8b), $7.5 \mathrm{~cm}$ (Fig. 8c) and in the last configuration before collapse (Figs. 8de), respectively.

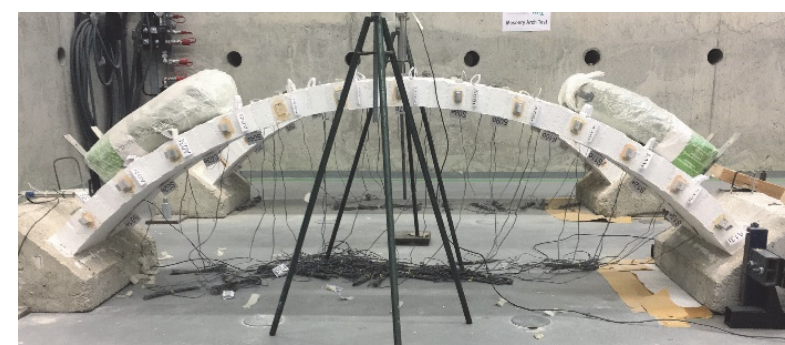

(a)

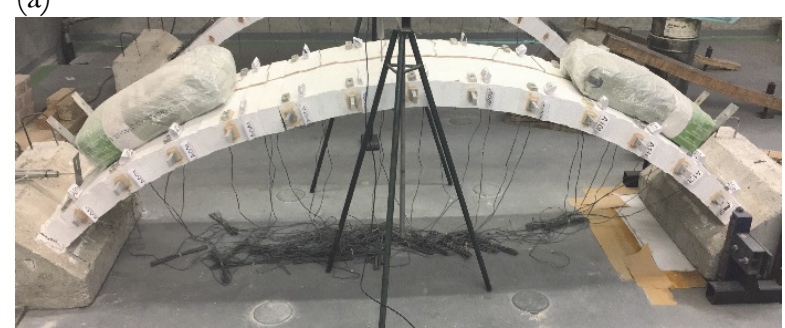

(b)
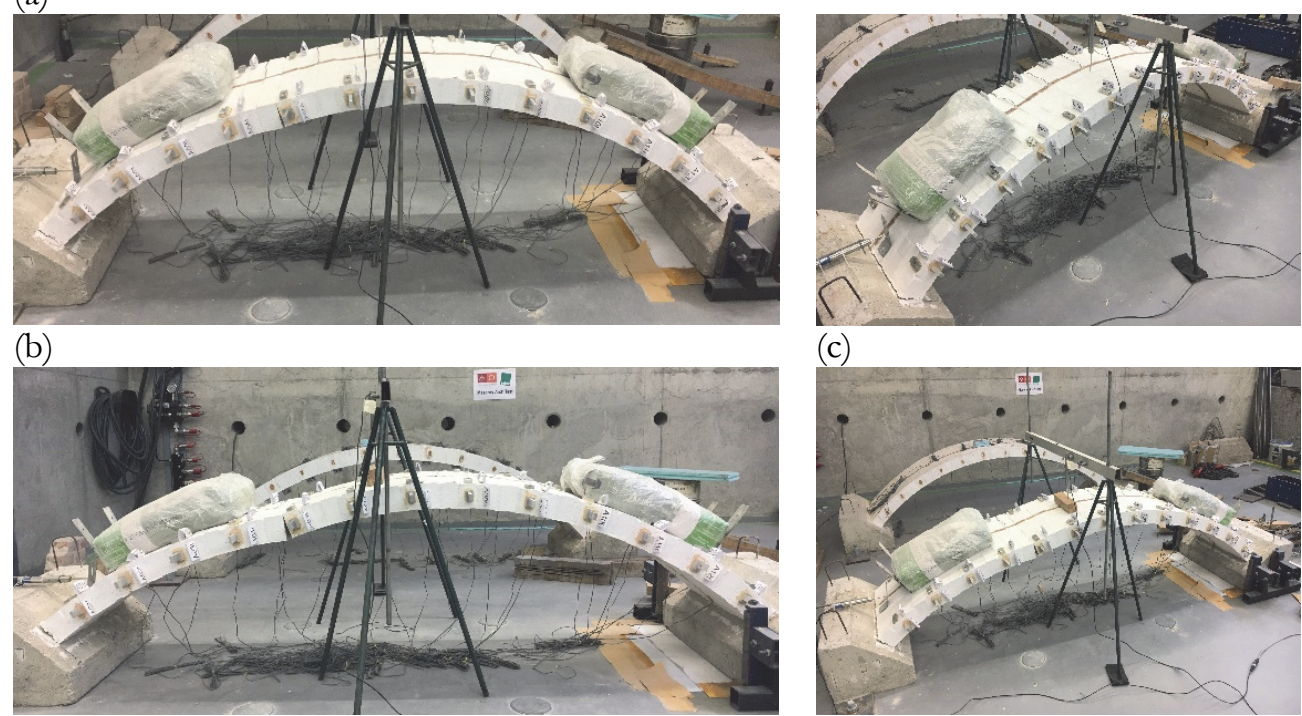

(d)

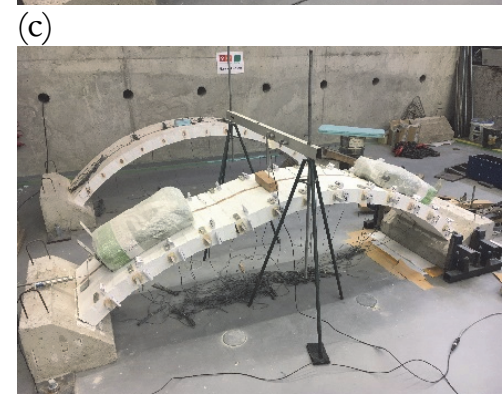

(e)

Figure 8: Experimental kinematic configurations of the segmental masonry arch subjected to horizontal settlements of the right support: (a) $0.5 \mathrm{~cm}$; (b) $4.5 \mathrm{~cm}$; (c) $7.5 \mathrm{~cm}$; (d) and (e) $10.5 \mathrm{~cm}$ settlements.

The maximum measured displacement before collapse $(10.5 \mathrm{~cm})$ was reached with an increment of $5.5 \%$ with respect to the nominal span. At this stage, the position of the thrust line still lies inside the profile of the arch (even if it is close to touch the intrados in correspondence of the 11th joint from the right) confirming that the equilibrium of the structure with $10.5 \mathrm{~cm}$ settlement is still ensured. Afterwards, the right support is left free to slide horizontally over the clearance remaining between support and actuator $(3 \mathrm{~cm})$ with consequent loss of stability of the arch and activation of a pure rotational collapse mechanism when the thrust line becomes tangent to the arch profile in another point [19], presumably the 11th joint (counting from the moving support). The position of both intrados and extrados crack hinges remains unchanged throughout the development of the mechanism. Collapse occurs with a limit displacement capacity of approximately $12 \mathrm{~cm}$, corresponding to an ultimate span increment of 6.3\%. In Fig. 9 the instant immediately after the collapse is shown.

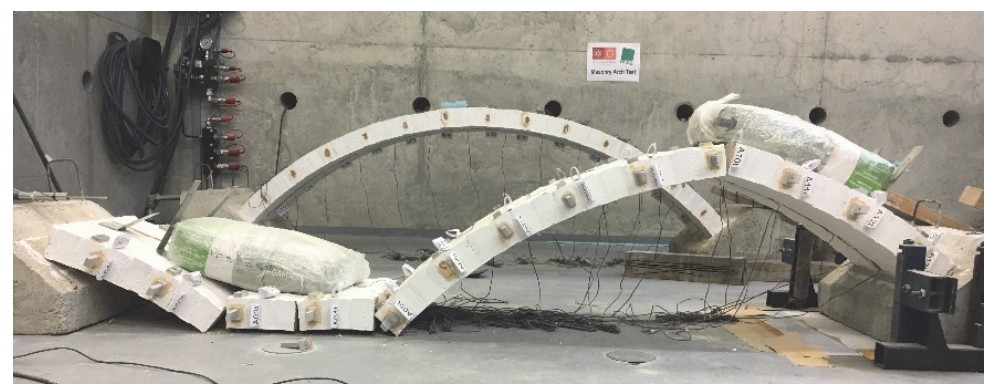

Figure 9: Masonry arch specimen after collapsing due to increasing horizontal settlements of the right support. 


\section{NUMERICAL MODELING}

$\mathrm{W}$

ith the aim of reproducing the dynamic behavior identified in the various damage scenarios, the segmental masonry arch described in the previous section was then modeled by a non-commercial finite element (FE) code. In particular, the adopted numerical procedure allowed to take into account the influence of the damage on the structure's dynamic properties in an automatically way, without resorting to the reduction of the elastic modules of the damaged zone, as usually done in the literature [31, 32].

\section{Constitutive equations and modal analysis of masonry structures}

Standard modal analysis allows to evaluate the dynamic properties of a structure. This analysis is based on the assumption that the materials constituting the structure are linear elastic, and can be unsuited to be applied to masonry constructions that exhibit a nonlinear behavior and show cracks (either due to permanent and/or accidental loads) which tend to reduce the structural stiffness, hence the frequencies. For these reasons, the dynamic behavior of masonry structures should be evaluated considering the presence of existing cracks. To this end, the FE NOSA-ITACA code [33],[34], developed by the Mechanics of Materials and Structures Laboratory of ISTI-CNR, adopts a numerical method based on linear perturbation and modal analysis, which takes into account the influence of existing damage on the dynamic properties of masonry buildings. The numerical method is widely described in $[35,36]$.

The NOSA-ITACA code allows to study the nonlinear behavior of masonry structures by adopting the constitutive equation of masonry-like materials. Masonry is modeled as a nonlinear elastic isotropic material with zero or weak tensile strength and infinite or bounded compressive strength [37,38]. Given the infinitesimal strain tensor $\mathbf{E}$, it is possible to prove the existence of a unique triplet $\left(\mathbf{T}, \mathbf{E}^{e}, \mathbf{E}^{f}\right)$ of symmetric tensors such that $\mathbf{E}$ is the sum of the elastic strain $\mathbf{E}^{e}$ and the positive semidefinite fracture strain $\mathbf{E}^{f}$, and the Cauchy stress $\mathbf{T}$, negative semidefinite and orthogonal to $\mathbf{E} f$, depends linearly and isotropically on $\mathbf{E}^{e}$, through the Young's modulus $E$ and Poisson's ratio $v[37,38]$. Masonry-like materials are then characterized by the stress function $T$ given by $T(\mathbf{E})=\mathbf{T}$, whose explicit expression is reported in [38], along with its main properties. In particular, $\mathrm{T}$ is differentiable on an open dense subset of the set of all strains and the explicit expression of the derivative $D_{\mathrm{E}} \mathrm{T}(\mathbf{E})$ of $\mathrm{T}(\mathbf{E})$ with respect to $\mathbf{E}$ is reported in [38]. The equation of masonry-like materials was then generalized in order to take into account a weak tensile strength $\sigma_{t} \geq 0$ [38].

The procedure implemented in the NOSA-ITACA code to evaluate the dynamic properties of masonry structures in the presence of cracks consists in calculating the numerical solution to the nonlinear equilibrium problem of a masonry structure discretized into finite elements, subjected to given boundary and loading conditions, and then solving the generalized eigenvalues problem:

$$
K_{T} \phi=\omega^{2} M \phi
$$

obtained from the linear equation governing the undamped free vibrations of the structure about the equilibrium solution. $K_{T}$ and $M \in \mathbf{R}^{n \times n}$ are the tangent stiffness and mass matrices of the finite-element assemblage, both symmetric and positive definite, $\phi$ is a vector of $\mathbf{R}^{n}$ and $\omega$ a real scalar, with $n$ the number of degrees of freedom of the structure. The counterpart of Eq. (1) for a linear elastic body involves the elastic stiffness matrix $K_{E}$, replaced in (1) by the tangent stiffness matrix $K_{T}$, calculated using the solution to the equilibrium problem and then taking into account the presence of cracks in the body. Therefore, assigned a case-study structure discretized into finite elements, and given the mechanical properties of the constituent materials together with the kinematic constraints and loads acting on the structure, the procedure implemented in NOSA-ITACA consists of the following two steps: 1) solution of the nonlinear equilibrium problem of the masonry structure subjected to external loads and calculation of the tangent stiffness matrix $K_{T}$ to be used in the next step; 2) solution of the generalized eigenvalue problem (1), where the matrix $K_{T}$ is employed instead of its elastic counterpart, and the natural frequencies $f_{i}=\omega_{i} / 2 \pi$ and mode shapes $\phi_{i}$ of the structure are estimated in the presence of cracks [35, 36]. In particular, NOSA-ITACA provides the first $k$ natural frequencies $f_{1} \leq f_{2} \leq \ldots \leq f_{k}$ and the corresponding $M$-orthonormal mode shapes $\phi_{1}, \phi_{2}, \ldots, \phi_{k}[39]$.

\section{Reference scenarios model updating}

NOSA- ITACA is used to model the experimental specimen described in the previous section, employing 53,496 8-node isoparametric brick elements (element 8 of the NOSA-ITACA library [34]) and 64,411 nodes, for a total of 193,233 degrees 
of freedom. Fig. 10 shows the FE mesh generated by the code, where the individual masonry components, bricks and mortar joints, are highlighted in cyan and red, respectively, while the parts loaded with lime bags are displayed in yellow.

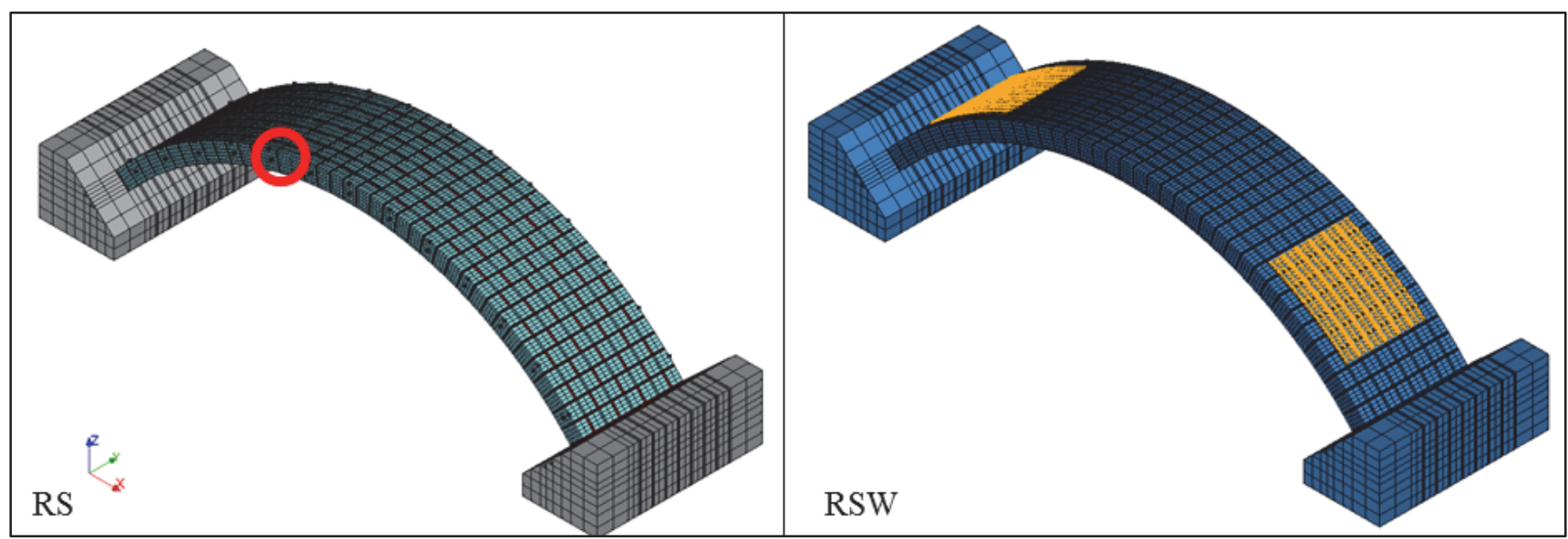

Figure 10: FE model of the experimental specimen generated by NOSA-ITACA for RS and RSW.

A model updating [40] is performed on the FE model with the aim of estimating the Young's moduli $E$ of the two masonry components (mortar and brick). The algorithm used and implemented in the NOSA-ITACA code for model updating is based on the construction of local parametric reduced order models embedded in a trust-region scheme. The objective function to be minimized is the distance between experimental and numerical natural frequencies and mode shapes. The optimal mechanical characteristics of the two masonry components are estimated by using the first three experimental frequencies and mode shapes of the reference scenario (RS), assumed as undamaged configuration, because the parameters to be optimized are only two. This choice is based on the observation that in both reference scenarios (RS and RSW) no visible cracks were present, thus the arch behavior can be plausibly considered as linear elastic at this stage. The model updating is carried out considering the base of the concrete supports clumped and adding concentrated masses to the measurement points (black nodes in Fig. 10) to take the weight of the accelerometers into account. Tab. 4 summarizes the mechanical characteristics of the materials employed in the FE model: in bold the parameter values obtained via model updating (the others, including the Poisson's ratios and mass densities, are kept fixed during the optimization process). It is interesting to note that the updated Young's moduli obtained through the aforementioned procedure are consistent with the values reported in literature [41, 42].

The modal results of the calibrated numerical model are summarized in Tab. 5 along with the experimental counterpart. The relative errors in frequencies and MAC values are also reported to assess the degree of consistency between experimental and numerical mode shapes for RS. It is worth noting that the fourth and fifth numerical mode shapes are inverted with respect to the corresponding experimental modes, as clearly shown in Fig. 11. Furthermore, the MAC value relative to the second mode shape is quite low. This is likely due to the fact that the numerical mode shape, being the model clamped at the base of both concrete abutments, is characterized by a displacement in $\mathrm{Y}$ direction coupled with a torsion around the $\mathrm{X}$ axis, while the corresponding experimental mode shape (as visible in Fig. 11 for RS, and even better in Fig. 13 for RSW) seems to be characterized by a movement in $\mathrm{Y}$ direction and a torsion around the $\mathrm{Z}$ axis, even though the moving support is nominally kept blocked in the reference configurations.

\begin{tabular}{cccc} 
& $E[\mathrm{MPa}]$ & $\nu$ & $\varrho\left[\mathrm{kg} / \mathrm{m}^{3}\right]$ \\
Brick & $\mathbf{2 5 0 0}$ & 0.2 & 1653.3 \\
Mortar & $\mathbf{5 0 0}$ & 0.2 & 1750.0 \\
Concrete & 25000 & 0.2 & 2500.0 \\
\hline
\end{tabular}

Table 4: Materials properties adopted for the numerical model. 


\begin{tabular}{cccc|ccccc}
\hline RS & $f_{\text {exp }}$ & $f_{\text {num }}$ & $|\Delta f|[\%]$ & \multicolumn{5}{c}{ MAC $\left(\phi_{\text {exp }}, \phi_{\text {num }}\right)$} \\
Mode 1 & 37.03 & 36.55 & 1.30 & $\mathbf{0 . 9 4}$ & 0.00 & 0.01 & 0.00 & 0.02 \\
Mode 2 & 58.64 & 55.57 & 5.24 & 0.01 & $\mathbf{0 . 7 2}$ & 0.15 & 0.01 & 0.00 \\
Mode 3 & 63.56 & 65.87 & 3.63 & 0.04 & 0.02 & $\mathbf{0 . 8 1}$ & 0.04 & 0.00 \\
Mode 4 & 100.76 & 114.34 & 13.49 & 0.10 & 0.00 & 0.03 & 0.01 & $\mathbf{0 . 5 6}$ \\
Mode 6 & 125.06 & $124.08^{*}$ & 0.79 & 0.00 & 0.00 & 0.12 & $\mathbf{0 . 8 7}$ & 0.00 \\
\hline
\end{tabular}

Table 5: Experimental $\left(f_{\text {exp }}\right)$ versus numerical frequencies $\left(f_{\text {num }}\right)$, frequency relative error $\Delta f$ and MAC matrix for the Reference Scenario (RS). Note: * refers to the frequency of the fifth numerical mode.

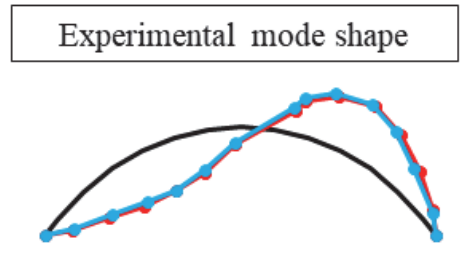

Mode $1, f=37.03 \mathrm{~Hz}$

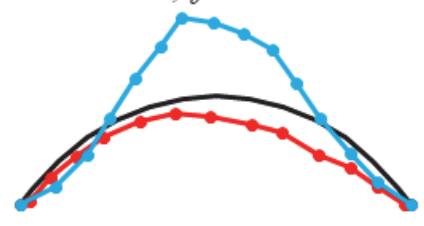

Mode 2, $f=58.64 \mathrm{~Hz}$

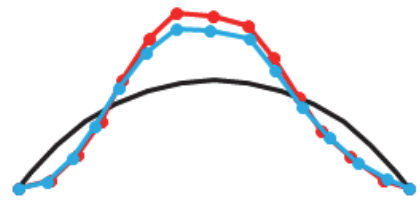

Mode $3, f=63.56 \mathrm{~Hz}$

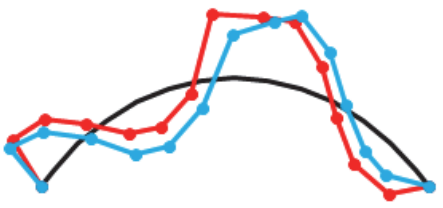

Mode $4, f=100.76 \mathrm{~Hz}$

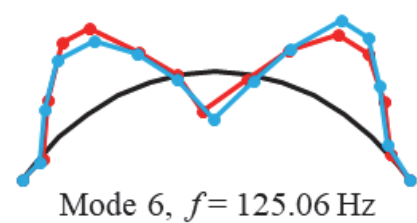

\section{Numerical mode shape}
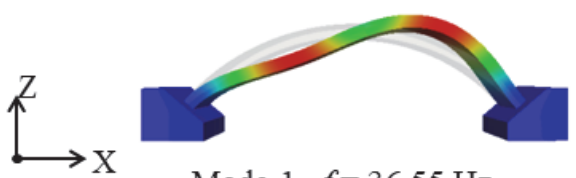

Mode $1, f=36.55 \mathrm{~Hz}$

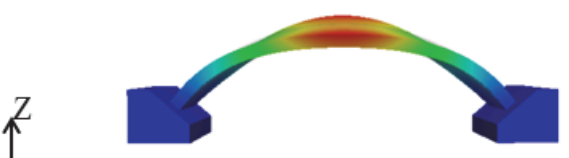

Mode 2, $f=55.57 \mathrm{~Hz}$

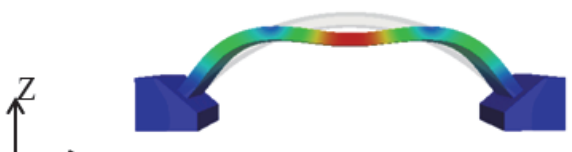

Mode $3, f=65.87 \mathrm{~Hz}$
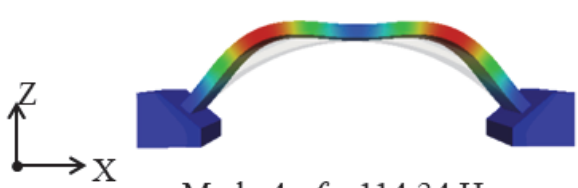

Mode $4, f=114.34 \mathrm{~Hz}$

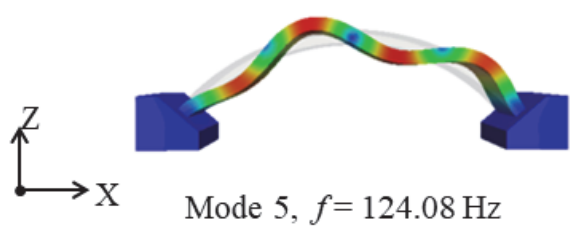

Figure 11: Experimental (left) and numerical (right) mode shapes for Reference Scenario RS (blue line: front side A01-A13; red line: back side A14-A26).

With the purpose of matching the order of fourth and fifth mode shapes, a parametric study on the boundary conditions of the right abutment is conducted by introducing horizontal and vertical springs aimed at simulating the friction effect between the moving support and the ground floor, as well as its possible rotation. The analyses carried out varying the 
stiffness of the springs reveal that the ordering of the mode shapes remains unchanged and the MAC values related to the first three eigenfrequencies get worse.

As a second attempt a numerical simulation is performed reducing the mortar joint thickness as done in [3, 43, 44], fact that can be reasonably justified by the necessity to take into account the slight variations in thickness, corner rounding and imperfections typical of a manually assembled geometry. The results obtained by this simulation show that the only way to invert fourth and fifth mode shapes is to reduce the mortar joint thickness at least of $20 \%$. This allows to infer that mechanical uncertainties, geometrical imperfections and block size variations do affect not only the overall capacity of an arch, but also its dynamic properties [45]. Fig. 12 shows the variation of the fourth and fifth vibration mode of the arch as a function of the mortar joint thickness. As clearly discernible in the Figure, when the thickness of the mortar joints is about $0.063 \mathrm{~m}$ the two frequencies coincide and the corresponding mode shapes switch. However, this modeling strategy can be exclusively adopted for the RS configuration, as it proves not to be suitable for simulating the arch dynamic behavior neither in the RSW configuration nor in the subsequent damage scenario (DS1), where the sixth experimental mode characterized by a "heart shape" disappears (or it is no longer identifiable). In addition, reducing the joint thickness causes the second and third numerical mode shapes to invert. Due to these reasons, no thickness reduction is applied to the model and only the first four corresponding modes are taken into account for the linear perturbation adopted next. Fig. 13 shows the considered experimental and numerical mode shapes for the RSW configuration; the numerical results are obtained using the parameters provided in Tab. 4 and applying to the FE model (Fig. 10) a total mass of $50 \mathrm{~kg}$ to simulate the lime bags symmetrically placed on the arch backs.

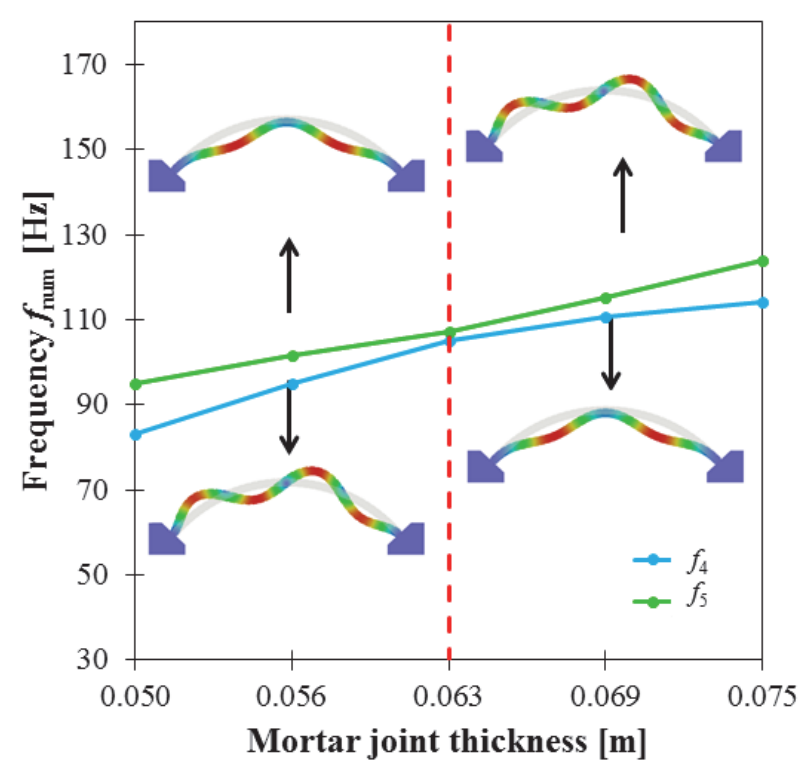

Figure 12: Fourth and fifth mode trend vs mortar joint thickness.

Tab. 6 summarizes both experimental and numerical frequencies for RSW as well as the MAC matrix between experimental and numerical mode shapes.

\begin{tabular}{cccc|cccc}
\hline RSW & $f_{\text {exp }}$ & $f_{\text {num }}$ & $|\Delta f|[\%]$ & \multicolumn{4}{c}{ MAC $\left(\phi_{\text {exp }}, \phi_{\text {num }}\right)$} \\
Mode 1 & 30.06 & 30.84 & 2.60 & $\mathbf{0 . 9 5}$ & 0.00 & 0.00 & 0.02 \\
Mode 2 & 50.95 & 52.75 & 3.53 & 0.01 & $\mathbf{0 . 6 5}$ & 0.00 & 0.00 \\
Mode 3 & 59.44 & 58.74 & 1.18 & 0.00 & 0.01 & $\mathbf{0 . 7 9}$ & 0.01 \\
Mode 4 & 95.23 & 104.61 & 9.85 & 0.22 & 0.00 & 0.02 & $\mathbf{0 . 6 5}$ \\
\hline
\end{tabular}

Table 6: Experimental $\left(f_{\text {exp }}\right)$ versus numerical frequencies $\left(f_{\text {num }}\right)$, frequency relative error $\Delta f$ and MAC matrix for RSW. 


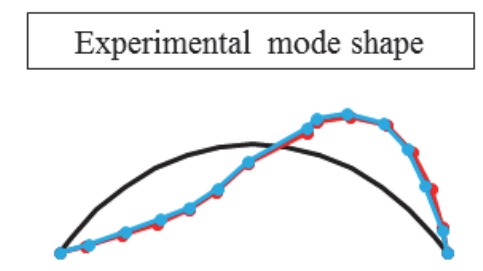

Mode $1, f=30.06 \mathrm{~Hz}$

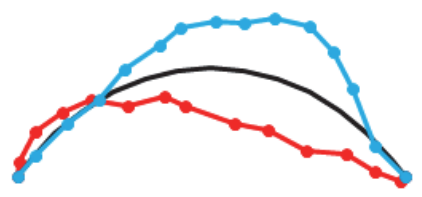

Mode $2, f=50.95 \mathrm{~Hz}$

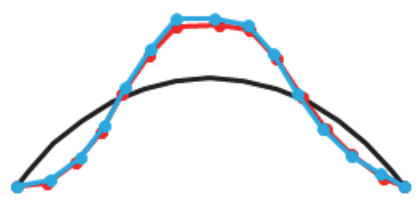

Mode 3, $f=59.44 \mathrm{~Hz}$

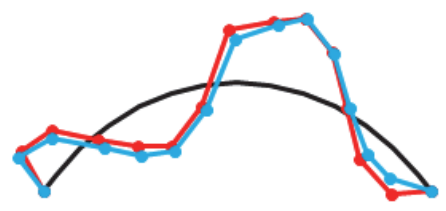

Mode $4, f=95.23 \mathrm{~Hz}$

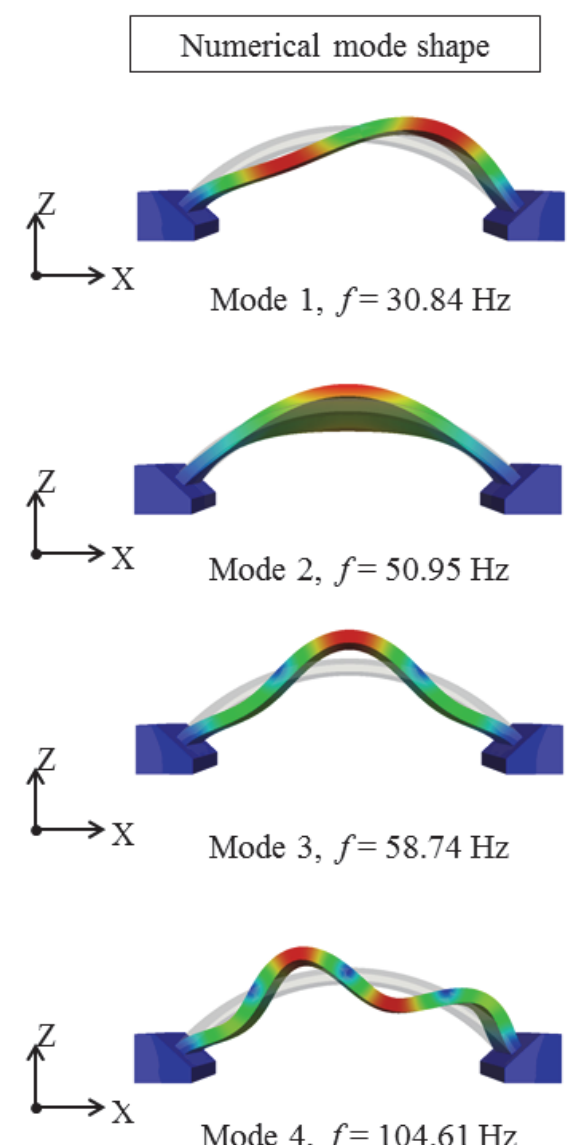

Mode 4, $f=104.61 \mathrm{~Hz}$

Figure 13: Experimental (left) and numerical (right) mode shapes for Reference Scenario with Weight RSW (blue line: front side A01A13; red line: back side A14-A26).

\section{Damage scenarios simulation}

Using the FE model calibrated through the standard model updating sketched in the previous subsection, a linear perturbation followed by modal analysis is conducted via the NOSA-ITACA code according to the procedure described in Section 0, modeling concrete as a linear elastic material, bricks and mortar as masonry-like materials. A further model updating is conducted by keeping the values of $E, v$ and $\varrho$ fixed (Tab.4) and varying the tensile strengths of brick $\left(\sigma_{t}=0.5 \mathrm{MPa}\right)$ and $\operatorname{mortar}\left(\sigma_{t}=0.37 \mathrm{MPa}\right)$.

In order to numerically reproduce the experimental crack pattern along with its evolution [46], the tensile strength of the mortar joint circled in red in Fig. 10 is reduced of about $80 \%$. Each analysis is conducted by imposing the same horizontal displacements (X direction) recorded during the experimental test to all nodes belonging to the base of the right abutment (moving support). As an example, the comparison between numerical and experimental results for DS3 and DS5 is summarized in Tab. 7 and Tab. 8, highlighting percentage frequency errors and MAC values between corresponding vibration modes. A visual comparison between experimental and numerical mode shapes for damage scenarios DS3 and DS5 is given in Figs 14 and 15.

\begin{tabular}{cccc|cccc}
\hline DS3 & $f_{\text {exp }}$ & $f_{\text {num }}$ & $|\Delta f|[\%]$ & \multicolumn{4}{c}{ MAC $\left(\phi_{\text {exp }}, \phi_{\text {num }}\right)$} \\
Mode 1 & 21.45 & 22.13 & 3.17 & $\mathbf{0 . 9 7}$ & 0.00 & 0.00 & 0.01 \\
Mode 2 & 45.14 & 48.96 & 8.46 & 0.01 & $\mathbf{0 . 8 0}$ & 0.00 & 0.00 \\
Mode 3 & 58.27 & 53.24 & 8.62 & 0.05 & 0.00 & $\mathbf{0 . 7 9}$ & 0.07 \\
Mode 4 & 74.97 & 73.32 & 2.20 & 0.09 & 0.00 & 0.01 & $\mathbf{0 . 8 8}$ \\
\hline
\end{tabular}

Table 7: Experimental $\left(f_{\text {exp }}\right)$ versus numerical frequencies $\left(f_{\text {num }}\right)$, frequency relative error $\Delta f$ and MAC matrix for DS3. 


\begin{tabular}{cccc|cccc}
\hline DS5 & $f_{\text {exp }}$ & $f_{\text {num }}$ & $|\Delta f|[\%]$ & \multicolumn{4}{c}{ MAC $\left(\phi_{\text {exp }}, \phi_{\text {num }}\right)$} \\
Mode 1 & 19.16 & 17.44 & 8.97 & $\mathbf{0 . 9 8}$ & 0.00 & 0.00 & 0.01 \\
Mode 2 & 43.19 & 44.11 & 2.13 & 0.00 & $\mathbf{0 . 7 9}$ & 0.02 & 0.00 \\
Mode 3 & 57.54 & 48.18 & 16.27 & 0.07 & 0.00 & $\mathbf{0 . 7 9}$ & 0.10 \\
Mode 4 & 74.09 & 61.00 & 17.67 & 0.08 & 0.00 & 0.00 & $\mathbf{0 . 8 9}$ \\
\hline
\end{tabular}

Table 8: Experimental $\left(f_{\text {exp }}\right)$ versus numerical frequencies $\left(f_{\text {num }}\right)$, frequency relative error $\Delta f$ and MAC matrix for DS5.

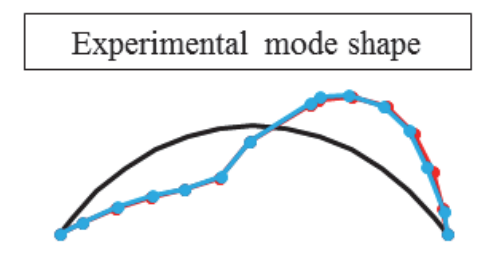

Mode $1, f=21.45 \mathrm{~Hz}$

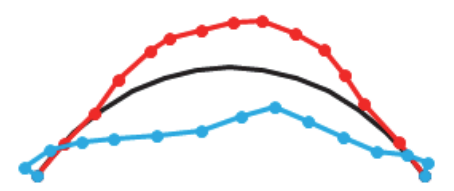

Mode $2, f=45.14 \mathrm{~Hz}$

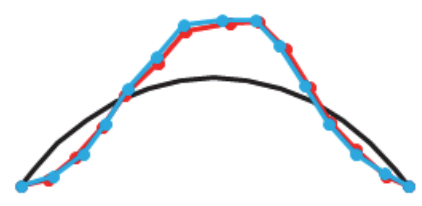

Mode $3, f=58.27 \mathrm{~Hz}$

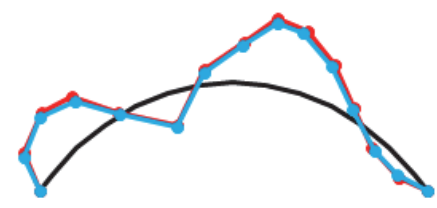

Mode $4, f=74.97 \mathrm{~Hz}$

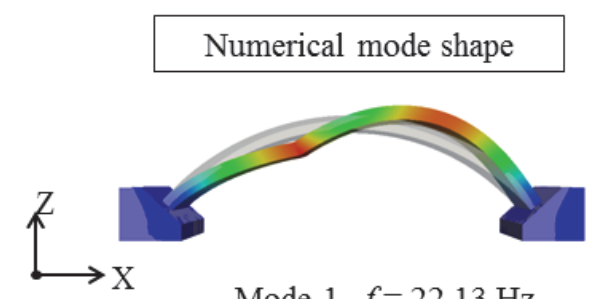

Mode $1, f=22.13 \mathrm{~Hz}$

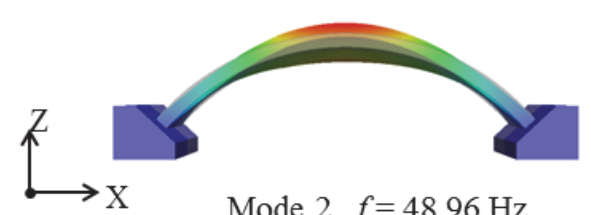

Mode $2, f=48.96 \mathrm{~Hz}$
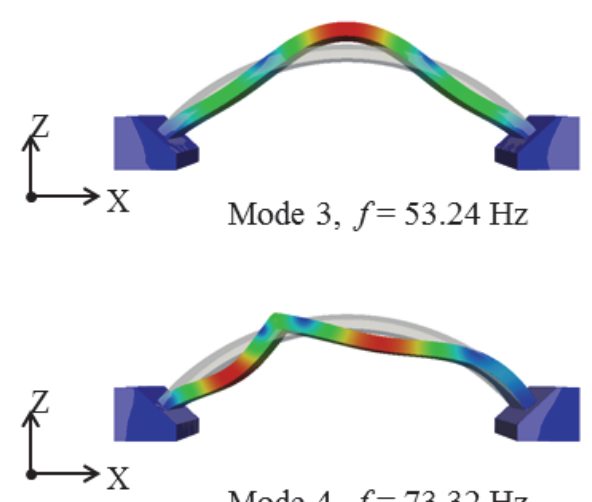

Mode $4, f=73.32 \mathrm{~Hz}$

Figure 14: Experimental (left) and numerical (right) mode shapes for Damage Scenario DS3 (blue line: front side A01-A13; red line: back side A14-A26).

Fig. 16 shows the trend of the arch frequencies over progressive support settlements in the experimental and numerical cases. It appears that the adopted numerical simulation coupling linear perturbation and modal analysis is able to fairly replicate the dynamic behavior of the damaged arch, especially with regard to the mode shapes, while it underestimates for the last DS the frequencies relative to the third and fourth modes.

For the sake of completeness, the distribution of the maximum eigenvalue of the fracture strain tensor $\mathbf{E}^{f}$ and of the minimum eigenvalue of the Cauchy stress tensor $\mathbf{T}$ concerning the last damage scenario (DS5) are displayed in Figs. 17 and 18, further demonstrating the consistency between numerical and experimental crack pattern. 


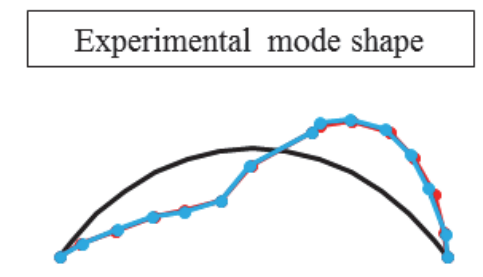

Mode $1, f=19.16 \mathrm{~Hz}$

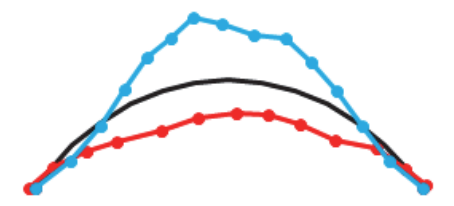

Mode $2, f=43.19 \mathrm{~Hz}$

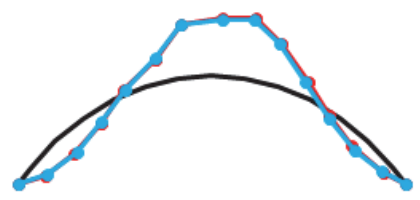

Mode $3, f=57.54 \mathrm{~Hz}$

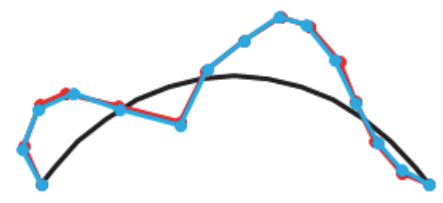

Mode $4, f=74.09 \mathrm{~Hz}$
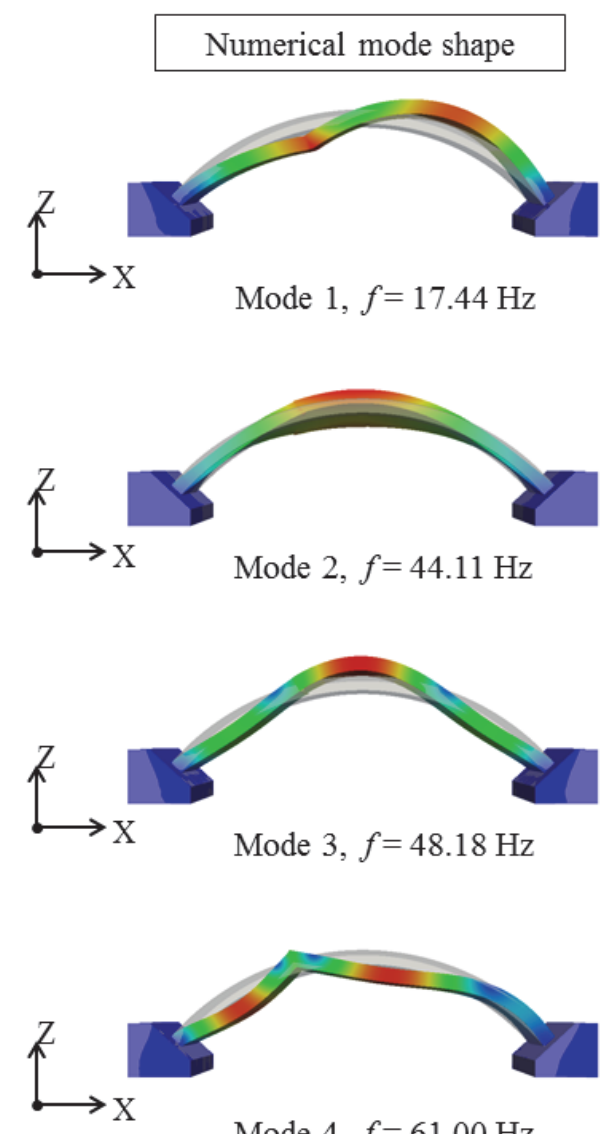

Mode $4, f=61.00 \mathrm{~Hz}$

Figure 15: Experimental (left) and numerical (right) mode shapes for Damage Scenario DS5 (blue line: front side A01-A13; red line: back side A14-A26).
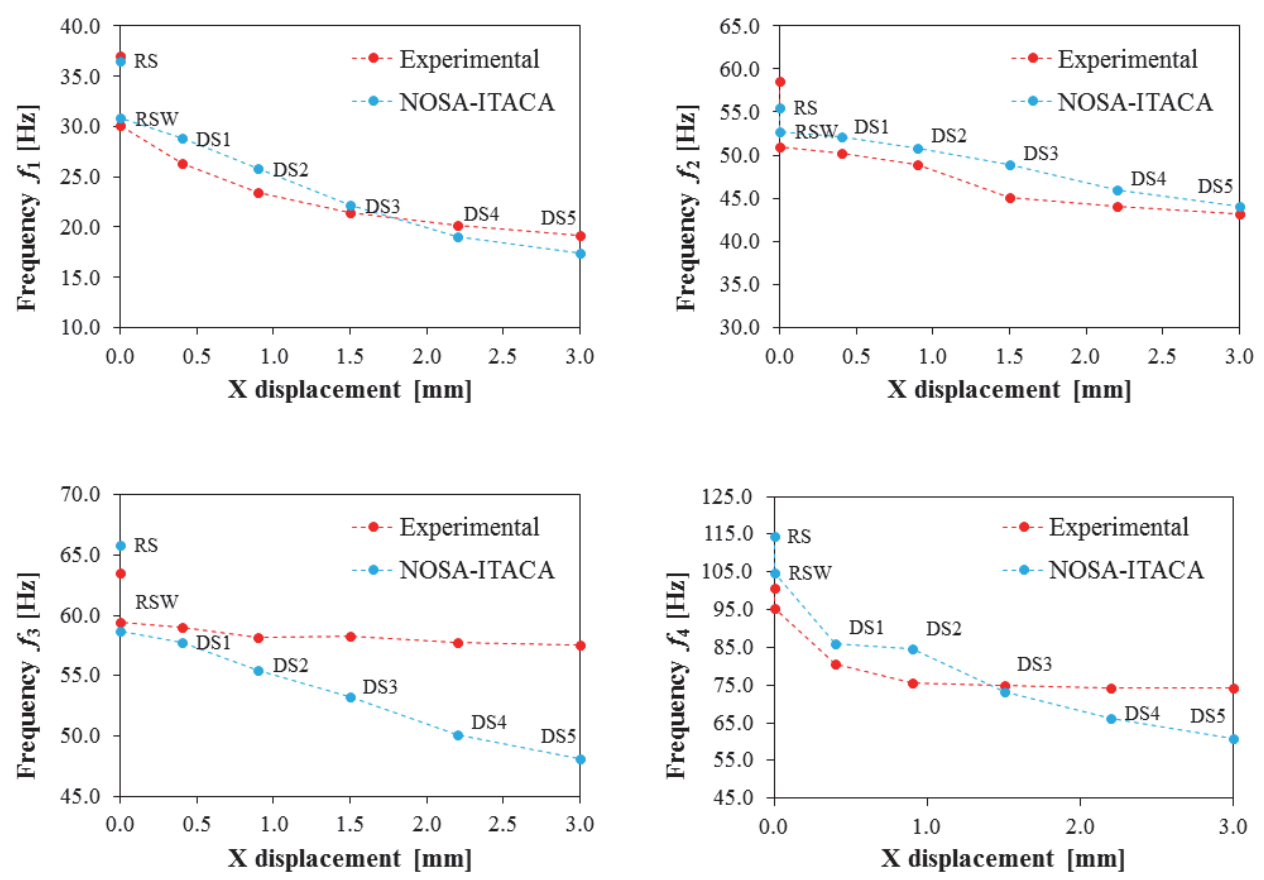

Figure 16: Trend of the first four frequencies of the arch versus abutment settlement for DS3 and DS5. 

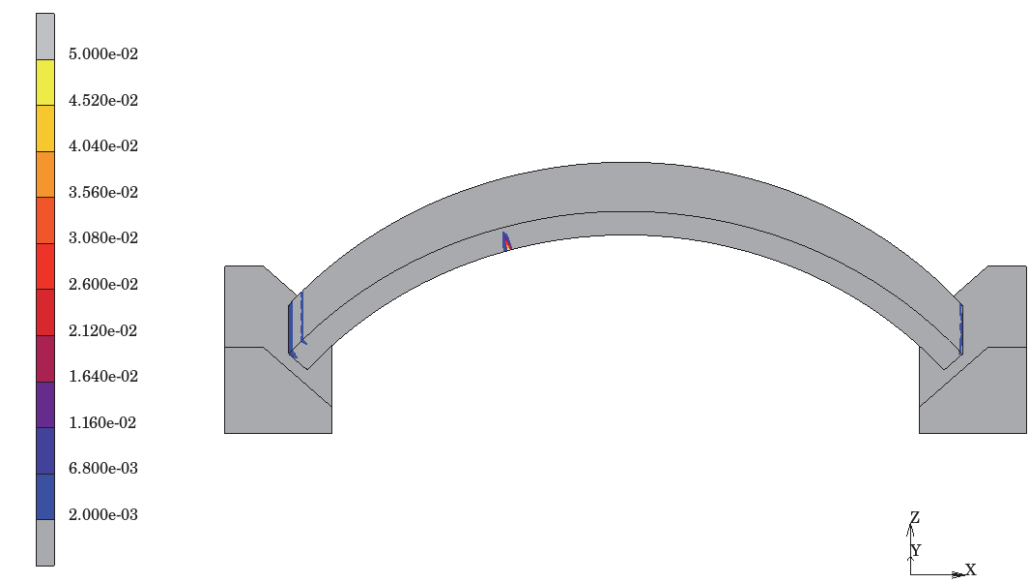

Figure 17: Maximum eigenvalue of the fracture strain tensor $\mathbf{E}^{f}$ at scenario DS5.
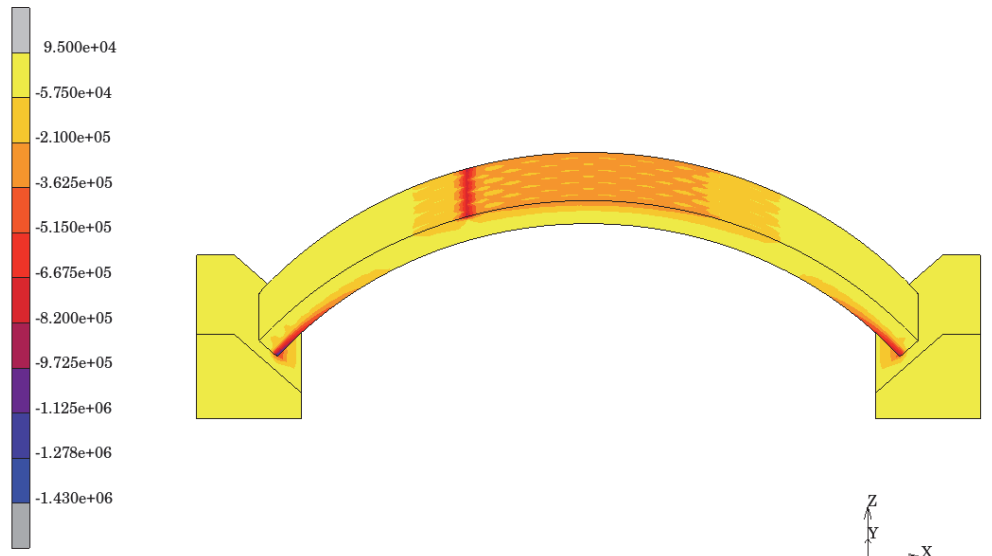

Figure 18: Minimum eigenvalue of the stress tensor $\mathbf{T}[\mathrm{Pa}]$ at scenario DS5.

\section{CONCLUSIONS}

$\mathrm{S}$ ettlements represent one of the main causes of collapse in arched structures and not all the aspects related to this phenomenon have been completely explored in the literature, as for instance their effects on arches dynamic properties. The correct dynamic characterization of this kind of structures undergoing supports settlements is fundamental to timely detect the occurrence of serious damage mechanisms and prevent unexpected failures.

This paper focused on the dynamic characterization of a segmental masonry arch with one settled support, from both the experimental and the numerical point of view. The arch specimen, tested in the Structural Laboratory of University of Minho, was progressively damaged by applying uniform increasing displacements at one abutment. After each displacement stage, dynamic identification tests were performed to estimate, via the Enhanced Frequency Domain Decomposition and the Stochastic Subspace Identification methods, the modal characteristics of the system in terms of frequencies, mode shapes and damping ratios. Despite the low displacement rate applied to the support, significant changes affected the eigenfrequencies and damping ratios of the arch; in particular, decreases of about $36 \%$ and $22 \%$ were recorded for the first and fourth eigenfrequencies as a consequence of a total settlement of $3 \mathrm{~mm}$. This fact is likely connected to the deformations associated to the first and fourth mode shapes of the arch (anti-symmetric eigenmodes) due to the abutment settlement. Analyzing the evolution of the modal features allows quantifying the effects that the spreading supports can have on the dynamic behavior of segmental masonry arches, both at global and local levels, and demonstrating the high vulnerability of such structures even to incipient support settlements.

From the numerical point of view, with the purpose of reproducing the dynamic behavior identified along the test stages, a numerical method relying on the coupled application of linear perturbation and modal analysis, implemented in the non- 
commercial finite element code NOSA-ITACA, was used. From comparison with the experimental results, it turns out that the adopted simulation is able to replicate the dynamic behavior of the damaged arch; numerical frequencies and mode shapes match their experimental counterparts, although in the last damage scenario the actual frequencies relative to the third and fourth modes are slightly overestimated. In view of the sensitivity of the experimental and numerical results to the geometrical features of the arch and manual assemblage adopted, further laboratory tests and FE analyses may be required to refine the numerical prediction strategy.

\section{REFERENCES}

[1] Levy, M. (2006). The Arch: Born in the Sewer, Raised to the Heavens, Nexus Network Journal. 8, pp. 7-12.

[2] Pelà, L., Aprile, A. and Benedetti, A. (2009) Seismic assessment of masonry arch bridges, Eng Struct. 31, pp. 17771788. doi: 10.1016/j.engstruct.2009.02.012

[3] Gaetani, A., Lourenco, P.B., Monti, G., and Moroni, M. (2017). Shaking table tests and numerical analyses on a scaled dry-joint arch undergoing windowed sine pulses. Bull Earthquake Eng, 15, pp. 4939-4961.

[4] De Santis, S. and de Felice, G. (2014). A fibre beam-based approach for the evaluation of the seismic capacity of masonry arches. Earthq Eng Struct Dyn, 43, pp. 1661-1681. doi: 10.1002/eqe.2416

[5] Cavalagli, N., Gusella, V. and Severini, L. (2017). The safety of masonry arches with uncertain geometry. Comput Struct, 188, pp. 17-31.

[6] Sánchez-Aparicio, L.J. et al. (2019). Non-destructive means and methods for structural diagnosis of masonry arch bridges. Automation in Construction, 104, pp. 360-382.

[7] Conde, B. et al. (2017). Structural assessment of masonry arch bridges by combination of non-destructive testing techniques and three-dimensional numerical modelling: Application to Vilanova bridge. Engineering Structures, 148, pp. 621-638.

[8] de Arteaga, I. and Morer, P. (2012). The effect of geometry on the structural capacity of masonry arch bridges. Constr Build Mater, 34, pp. 97-106.

[9] Conde, B., Díaz-Vilariño, L., Lagüela, S., and Arias, P. (2016). Structural analysis of Monforte de Lemos masonry arch bridge considering the influence of the geometry of the arches and fill material on the collapse load estimation. Constr Build Mater, 120, pp. 630-42.

[10] Severini, L., Cavalagli, N., DeJong, M. and Gusella, V. (2018). Dynamic response of masonry arch with geometrical irregularities subjected to a pulse-type ground motion. Nonlinear Dyn, 91(1), pp. 609-24.

[11] Milani, G. and Lourenço, P.B. (2012). 3D non-linear behavior of masonry arch bridges. Comput Struct, 110-111, pp. 133-150.

[12] Cavicchi, A. and Gambarotta, L. (2007). Lower bound limit analysis of masonry bridges including arch-fill interaction. Eng Struct, 29(11), pp. 3002-3014.

[13] Zampieri, P., Zanini, M., and Faleschini, F. (2016). Influence of damage on the seismic failure analysis of masonry arches. Constr Build Mater, 119, pp. 343-355.

[14]Zanaz, A., Yotte, S., Fouchal, F. and Chateauneuf, A. (2016). Efficient masonry vault inspection by monte carlo simulations: case of hidden defect. Case Stud Struct Eng, 5, pp. 1-12.

[15] Sarhosis, V., De Santis, S. and de Felice, G. (2016). A review of experimental investigations and assessment methods for masonry arch bridges, Structure and Infrastructure Engineering, 12(11), pp. 1439-1464.

[16] Ochsendorf, J.A. (2006). The masonry arch on spreading supports. Struct Eng, 84(2), pp. 29-35.

[17]Zampieri, P., Faleschini, F., Zanini, M.A. and Simoncello, N. (2018). Collapse mechanisms of masonry arches with settled springing, Eng Struct, 156, pp. 363-374.

[18]Zampieri, P., Cavalagli, N., Gusella, V. and Pellegrino, C. (2018). Collapse displacements of masonry arch with geometrical uncertainties on spreading supports, Comput Struct, 208, pp. 118-129.

[19] Galassi, S., Misseri, G., Rovero, L. and Tempesta, G. (2018). Failure modes prediction of masonry voussoir arches on moving supports, Engineering Structures, 173, pp. 706-717.

[20] Coccia, S., Di Carlo, F. and Rinaldi, Z. (2015). Collapse displacements for a mechanism of spreading-induced supports in a masonry arch. Int J Adv Struct Eng, 7(3), pp. 307-20.

[21] Alvandi, A., and Cremona, C. (2006). Assessment of vibration-based damage identification techniques. Journal of Sound and Vibration, 292, pp. 179-202.

[22] Farrar, C.R. and Worden, K. (2007). An introduction to structural health monitoring. Philosophical Transactions of the Royal Society A, 365, pp. 303-315. 
[23] Ramos, L.F., Marques, L., Lourenço, P.B., De Roeck, G., Campos-Costa, A. and Roque, J. (2010). Monitoring historical masonry structures with operational modal analysis: two case studies. Mechanical Systems and Signal Processing, 24(5), pp. 1291-1305.

[24] Masciotta, M.G., Ramos, L.F., Lourenço, P.B. and Vasta, M. (2017). Spectral algorithm for non-destructive damage localisation: Application to an ancient masonry arch model. Mechanical Systems and Signal Processing, 84, pp. $286-307$.

[25] Masciotta, M.G., Ramos, L.F. and Lourenço, P.B. (2017). The importance of structural monitoring as a diagnosis and control tool in the restoration process of heritage structures: A case study in Portugal. Journal of Cultural Heritage, 27, pp. 36-47.

[26] Ubertini, F., Cavalagli, N., Kita, A. and Comanducci, G. (2018). Assessment of a monumental masonry bell-tower after 2016 Central Italy seismic sequence by long-term SHM. Bulletin of Earthquake Engineering, 16(2), pp. $775-801$.

[27] Heyman, J. (1982). The Masonry Arch. Ellis Horwood Ltd.

[28] ARTeMIS Modal 5.3.1.1, Structural Vibration Solutions A/S (2018).

[29] Liu, M. and Gorman, D.G. (1995). Formulation of Rayleigh damping and its extensions. Computers and Structures, $57(2)$, pp. 277-285.

[30] Gilbert, M. (2007). Limit analysis applied to masonry arch bridges: state-of-the-art and recent developments. ARCH 2007 - Proceeding of the 5th International Conference on Arch Bridges, pp. 13-28.

[31] Pineda, P. (2016). Collapse and upgrading mechanisms associated to the structural materials of a deteriorated masonry tower. Nonlinear assessment under different damage and loading levels. Eng. Fail. Anal. 63, pp. 72-93.

[32] Ramos, L.F., De Roeck, G., Lourenço, P.B. et al. (2010). Damage identification on arched masonry structures using ambient and random impact vibrations. Eng Struct, 32, pp. 146-162.

[33] Girardi, M. Padovani, C. and Pellegrini, D. (2015). The NOSA-ITACA code for the safety assessment of ancient constructions: a case study in Livorno. Advances in Engineering Software Journal, 89, pp. 64-76.

[34] Binante, V., Girardi, M., Padovani, C., Pasquinelli, G., Pellegrini, D., Porcelli, M., and Robol, L. NOSA-ITACA 1.1 ISTI-CNR, 2017-SW-013.

[35] Pellegrini, D., Girardi, M., Padovani, C. and Azzara, R.M. (2017). A new numerical procedure for assessing the dynamic behaviour of ancient of ancient masonry towers. In M. Papadrakakis, M. Fragiadakis (eds.) COMPDYN 2017 Computational Methods in Structural Dynamics and Earthquake Engineering, vol. 2, pp. 5045-5055, Rodhos.

[36] Girardi, M., Padovani, C. and Pellegrini, D. (2018). Modal analysis of masonry structures. Mathematics and Mechanics of Solids, SAGE Publications Ltd STM, First Published February 13.

[37] Del Piero, G. (1989). Constitutive equation and compatibility of the external loads for linear elastic masonry-like materials. Meccanica, 24, pp. 150-162.

[38] Lucchesi, M., Padovani, C., Pasquinelli, G. and Zani, N. (2008). Masonry constructions: mechanical models and numerical applications. Lecture Notes in Applied and Computational Mechanics, Springer-Verlag.

[39] Porcelli, M., Binante, V., Girardi, M., Padovani., C. and Pasquinelli, G. (2015). A solution procedure for constrained eigenvalue problems and its application within the structural finite-element code NOSA-ITACA. Calcolo, 52(2), pp. 167-189.

[40] Girardi, M., Padovani, C., Pellegrini, D. and Robol, L. (2019). Model Updating Procedure to Enhance Structural Analysis in FE Code NOSA-ITACA. J. Perform. Constr. Facil, 33(4): 04019041.

[41] Binda, L., Roberti, G.M. and Tiraboschi, C. (1996). Problemi di misura dei parametri meccanici della muratura e dei suoi componenti. Atti del Convegno Nazionale La Meccanica delle Murature tra Teoria e Progetto, Messina.

[42] Narayanan, S.P. and Sirajuddin, M. (2013). Properties of Brick Masonry for FE modeling. American Journal of Engineering Research, 1, pp. 6-11.

[43] DeJong, M., De Lorenzis, L., Adams, S. and Ochsendorf, J. (2008). Rocking stability of masonry arches in seismic regions. Earthq Spectra, 24, pp. 847-865.

[44] Albuerne, A., Williams, M. and Lawson, V. (2013). Prediction of the failure mechanism of arches under base motion using DEM based on the NSCD method. Wiadomos'ci Konserw, 34, pp. 41-47.

[45] Pepi, C. et al. (2017). Dynamic characterization of a severely damaged historic masonry bridge. Procedia Engineering, 199, pp. 3398-3403.

[46] Pellegrini, D., Girardi, M., Lourenco, P.B., Masciotta, M.G., Mendes, N., Padovani, C. and Ramos, L.F. (2018). Modal analysis of historical masonry structures: linear perturbation and software benchmarking. Construction and Building Materials, 189, pp. 1232-1250. 